\author{
UNIVERSIDADE DE SÃO PAULO \\ FACULDADE DE ODONTOLOGIA DE RIBEIRÃO PRETO
}

POLLIANA VILAÇA SILVA

Avaliação da capacidade de limpeza do canal radicular por meio de agentes quelantes e desmineralizantes: estudo, ex vivo, por MEV e espectrometria dos compostos 
POLLIANA VILAÇA SILVA

\title{
Avaliação da capacidade de limpeza do canal radicular por meio de agentes quelantes e desmineralizantes: estudo, ex vivo, por MEV e espectrometria dos compostos
}

\begin{abstract}
Dissertação apresentada à Faculdade de Odontologia de Ribeirão Preto da Universidade de São Paulo para obtenção do Grau de Mestre em Ciências - Programa: Odontologia Restauradora Área de Concentração: Odontologia Restauradora Opção: Endodontia.
\end{abstract}

Orientador: Prof. Dr. Antonio Miranda da Cruz Filho 
Autorizo a reprodução e divulgação total ou parcial deste trabalho, por qualquer meio convencional ou eletrônico, para fins de estudo e pesquisa, desde que citada a fonte.

Assinatura do autor:

Data:

Ficha catalográfica

Silva, Polliana Vilaça

Avaliação da capacidade de limpeza do canal radicular por meio de agentes quelantes e desmineralizantes: estudo, ex vivo,por MEV e espectrometria dos compostos. Ribeirão Preto, 2011.

80 p. : il. ; $30 \mathrm{~cm}$

Dissertação de Mestrado, apresentada à Faculdade de Odontologia de Ribeirão Preto/USP, Departamento de Odontologia Restauradora - Endodontia.

Orientador: Cruz Filho, Antonio Miranda

1. Agentes Desmineralizantes. 2. Agentes Quelantes. 3 Quitosana. 4. EDTA. 5. Ácido Cítrico. 6. Ácido Acético. 7. Smear Layer. 8. Microscopia Eletrônica de Varredura. 9. Espectrometria de Absorção Atômica. 
SILVA, P. V. Avaliação da capacidade de limpeza do canal radicular por meio de agentes quelantes e desmineralizantes: estudo, ex vivo, por MEV e espectrometria dos compostos, 2011, 80 p. Dissertação (Mestrado) - Faculdade de Odontologia de Ribeirão Preto, Universidade de São Paulo, Ribeirão Preto, 2011.

Aprovado em:

\section{Banca Examinadora}

Prof. Dr. Antonio Miranda da Cruz Filho (orientador)

Instituição: Faculdade de Odontologia de Ribeirão Preto - USP

Julgamento:

Assinatura:

Prof.(a) Dr.(a):

Instituição:

Julgamento:

Assinatura:

Prof.(a) Dr.(a):

Instituição:

Julgamento:

Assinatura: 

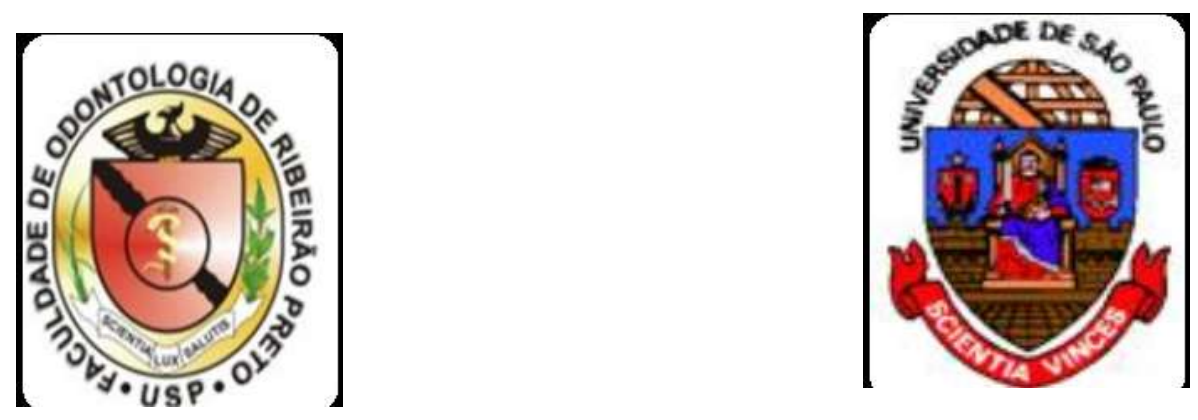

Este trabalho foi realizado no Laboratório de Pesquisa de Endodontia e no Laboratório de Pesquisa do Departamento de Odontologia Restauradora da Faculdade de Odontologia de Ribeirão Preto da Universidade de São Paulo. 


\section{DEDICATÓRIA}

Aos meus pais, Eleni e Célio, que me ensinaram que nessa vida é preciso: sabedoria, paciência, força e coragem na conquista dos objetivos.

Aos meus irmãos, Julianna e Leonardo, e meu cunhado Fábio pela grande amizade que nos liga, por acreditarem nas minhas escolhas e entenderem minha ausência em momentos importantes de suas vidas.

Ao meu marido, Antonio, pelo carinho e constante incentivo ao crescimento profissional, exigindo sempre minha superação.

A minha querida afilhada Giovanna. 


\section{AGRADECIMENTOS}

A Deus por guiar minha vida sempre.

Ao meu orientador Prof. Dr. Antonio Miranda da Cruz Filho pelos ensinamentos transmitidos, cooperação e imensa disponibilidade sempre que preciso. Obrigada por me orientar verdadeiramente nessa jornada.

Ao Prof. Dr. Jesus Djalma Pécora e ao Prof. Dr. Manoel Damião de Sousa Neto pelo constante incentivo à pesquisa. Por despertarem a curiosidade científica dos pós-graduandos sempre em busca de uma Endodontia mais eficaz.

Aos Professores do Departamento de Odontologia Restauradora da Faculdade de Odontologia de Ribeirão Preto, que por meio das disciplinas ministradas, contribuíram para meu crescimento profissional. 
À Prof ${ }^{a}$. Dra . Débora Fernandes Costas Guedes pela participação e amizade.

Aos funcionários da FORP-USP, em especial a Carlos Feitosa dos Santos, Reginaldo Santana da Silva, Luiza Godoi Pitol, Rosangela Angelini, Ronivaldo Zonfrilli e Frederico Augusto B. Farias por serem sempre prestativos e atenciosos.

À Cláudia Aparecida Rodrigues, técnica do laboratório de microscopia eletrônica da FCAV-UNESP, Jaboticabal, no auxílio do processamento das amostras da microscopia eletrônica, sempre com muito carinho e atenção.

A Flávio Venâncio Nakad, pelo auxílio na avaliação espectrométrica.

Ao querido Geraldo Celso Onety, amigo pra todas as horas.

Aos amigos do mestrado: Graziela Leoni, Luis Eduardo Flamini, Tiago Varise e Daniel Leonel, pela troca de conhecimentos e aprendizado.

Às minhas queridas amigas da graduação, pela amizade incondicional, em especial, a Sergilene Rodrigues Ferreira, irmã que a vida me presenteou.

Aos queridos Tios Reinaldo e Lina Azoubel, pelo incentivo, carinho e acolhimento.

À Faculdade de Odontologia de Ribeirão Preto - Universidade de São Paulo, pela oportunidade de formação profissional.

Ao Cnpq, pela bolsa de estudos outorgada.

Aos familiares e amigos, que sempre torceram pelo meu sucesso, em especial a Tia Edna, pelo seu carinho e orações. 
"É graça divina começar bem. Graça maior persistir na caminhada certa. Xas, graça das graças é não dessistir nunca." Dom Hélder Câmara 
RESUMO

SILVA, P. V. Avaliação da capacidade de limpeza do canal radicular por meio de agentes quelantes e desmineralizantes: estudo, ex vivo, por MEV e espectrometria dos compostos, 2011, 80 p. Dissertação (Mestrado) - Faculdade de Odontologia de Ribeirão Preto, Universidade de São Paulo, Ribeirão Preto, 2011.

O presente trabalho teve como objetivo avaliar, por meio da microscopia eletrônica de varredura (MEV), a capacidade de remoção da smear layer dos terços médio e apical do canal radicular utilizando soluções quelantes e desmineralizantes e, quantificar, por meio da espectrometria de absorção atômica com chama, a concentração de íons cálcio presentes nessas soluções após suas utilizações. Vinte e cinco caninos superiores foram preparados pela técnica Free Tip Preparation com 4 instrumentos acima do inicial e irrigados com hipoclorito de sódio $1 \%$ a cada troca de instrumento. Os dentes foram distribuídos aleatoriamente em 4 grupos, conforme protocolo utilizado para a irrigação final: G1 - EDTA 15\%, G2 - quitosana 0,2\%, G3 ácido cítrico 10\%, G4 - ácido acético $1 \%$. O grupo controle (G5) não recebeu irrigação. Foram utilizados $5 \mathrm{~mL}$ de cada solução por 3 minutos. Após percorrer toda extensão do canal radicular a solução extravasada pelo forame foi coletada e encaminhada para análise espectrométrica. Os espécimes foram seccionados longitudinalmente e preparados para análise em MEV. As fotomicrografias obtidas foram avaliadas qualitativamente por três examinadores, que atribuíram escores às imagens, conforme a quantidade de smear layer. Os dados obtidos pela MEV foram analisados estatisticamente por meio do Teste de Kruskal-Wallis e Dunn. Para avaliação da espectrometria utilizou-se Tukey-Kramer (one-Way ANOVA). Os resultados mostraram que o EDTA $15 \%$, quitosana $0,2 \%$ e ácido cítrico $10 \%$ removeram a smear layer de forma semelhante entre si e estatisticamente diferente $(p<0,05)$ do ácido ácético $1 \%$ e controle. Não houve diferença na capacidade de limpeza das soluções quando os terços médio e apical foram comparados. A maior concentração de íons cálcio foi observada no grupo do EDTA $15 \%$ e quitosana $0,2 \%$, sem diferença entre ambos. O grupo do ácido acético $1 \%$ apresentou as menores concentrações e o ácido cítrico $10 \%$, concentrações intermediárias e diferentes estatísticamente dos dois grupos $(p<0,01)$. Concluiu-se que as soluções de EDTA $15 \%$, quitosana $0,2 \%$ e ácido cítrico $10 \%$ foram eficientes na remoção da smear layer do terço médio e apical do canal radicular. As soluções de EDTA 15\% e quitosana $0,2 \%$ promoveram o maior efeito desmineralizante, seguidas pelo ácido cítrico $10 \%$ e acido acético $1 \%$.

Descritores: Agentes desmineralizantes, agentes quelantes, ácido cítrico, ácido acético, EDTA, quitosana, smear layer, Microscopia Eletrônica de Varredura, Espectrometria de absorção atômica. 


\section{ABSTRACT}

SILVA, P. V. Evaluation of the cleaning ability of root canal by means of chelating and demineralization agents: ex vivo study, SEM and atomic absorption spectrometry of the compounds. 2011. 80 p. Dissertação (Mestrado) Faculdade de Odontologia de Ribeirão Preto, Universidade de São Paulo, Ribeirão Preto, 2011.

This study aimed to evaluate, by scanning electron microscopy (SEM), the ability to remove the smear layer from the apical and middle thirds of the root canal using chelators and demineralizing solutions, and quantify, by atomic absorption spectrophotometry flame, the concentration of calcium ions present in these solutions after their use. Twenty-five canines were prepared by Free Tip Preparation Technique with four instruments above the initial and irrigated with $1 \%$ sodium hypochlorite in each change of instrument. The teeth were randomly divided into four groups, according to the protocol used for the final irrigation: G1 - EDTA 15\%, G2 $0.2 \%$ chitosan, G3 - citric acid 10\%, G4 - 1\% acetic acid. The control group (G5) did not receive irrigation. We used $5 \mathrm{~mL}$ of each solution for 3 minutes. After irrigating the entire length of the root canal through the apical foramen, the solution was collected and sent to spectrometric analysis. The specimens were sectioned longitudinally and prepared for SEM analysis. The photomicrographs were qualitatively evaluated by three observers, who attributed scores to the images, equivalent to the amount of smear layer removal. The data obtained by SEM was statistically analyzed using the Kruskal-Wallis and Dunn tests. To evaluate the spectrometer, the Tukey-Kramer (one-way ANOVA) was used. The results showed that $15 \%$ EDTA, $0.2 \%$ chitosan and $10 \%$ citric acid had a similar smear layer removal with statistically different $(p<0.05)$ when compared to $1 \%$ acetic acid and the control group. There was no difference between the solutions' cleaning ability when the middle and apical thirds were compared. The highest concentration of calcium ions was observed in $15 \%$ EDTA group and $0.2 \%$ chitosan, with no statistical difference between them. The 1\% acetic acid group had the lowest concentration and the 10\% citric acid intermediate concentrations with statistical difference between each other $(p<0.01)$. It can be concluded that the solutions of $15 \%$ EDTA, $0.2 \%$ chitosan and $10 \%$ citric acid were effective in removing the smear layer of the middle and apical thirds of the root canal. $15 \%$ EDTA solutions and $0.2 \%$ chitosan promoted the greatest effect on the demineralization, followed by $10 \%$ citric acid and $1 \%$ acetic acid.

Keywords: demineralization agents, chelating agents, citric acid, acetic acid, EDTA, chitosan, smear layer, scanning electron microscopy, atomic absorption spectrometry. 


\section{SUMÁRIO}

\section{RESUMO}

\section{ABSTRACT}

INTRODUÇÃO

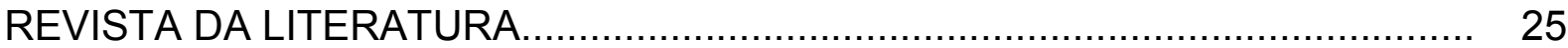

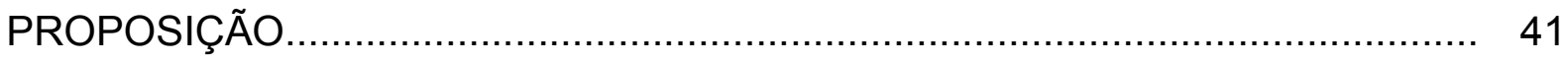

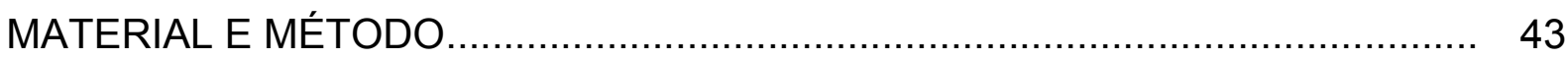

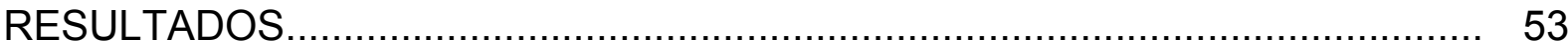

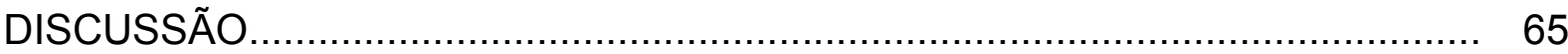

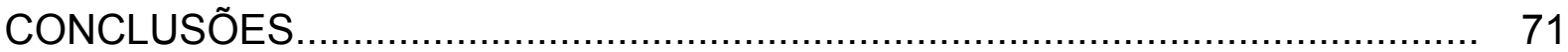

REFERÊNCIAS BIBLIOGRÁFICAS............................................................. 73

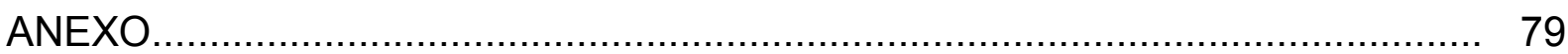




\section{INTRODUÇÃO}

O sucesso da terapia endodôntica é obtido quando há indicadores clínicos e radiográficos que evidenciem a ausência de sinais e sintomas de infecção ou inflamação, restabelecimento da função do elemento dentário e redução no tamanho e densidade da radiolucidez periapical anteriormente existente (ABBOT, 1991).

O êxito almejado no tratamento dos canais radiculares é dependente de vários fatores, como: a técnica empregada, propriedades físico químicas da solução irrigante utilizada, qualidade da sanificação e promoção da obturação tri-dimensional (SEN; WESSELINK; TÜRKÜN, 1995).

Dentre as etapas que compõem a terapêutica endodôntica, destaca-se o preparo biomecânico, o qual se caracteriza pelo debridamento e modelagem da geometria do canal radicular (MAHRAN; ABOEL-FOTOUH, 2008). No entanto, a ação dos instrumentos endodônticos junto às paredes dentinárias promove, inevitavelmente, a formação da smear layer, independentemente do tipo de instrumento utilizado ou da técnica estabelecida (VIOLICH; CHANDLER, 2010). Esta camada possui um aspecto granular, amorfo, irregular e é composta por matéria 
inorgânica (raspas de dentina contendo hidroxiapatita) e matéria orgânica (tecido pulpar vivo ou necrosado, remanescentes de odontoblastos, proteínas coaguladas, células sanguíneas, fibras nervosas, colágeno, fluido tissular, bactérias e seus subprodutos), associadas à solução irrigante utilizada (TORABINEJAD et al., 2002; KOKKAS et al., 2004).

A smear layer pode impedir ou dificultar consideravelmente a penetração de agentes antimicrobianos através dos túbulos dentinários, limitando uma efetiva desinfecção (ORSTAVIK; HAAPASALO, 1990), interferindo na adesão dos cimentos endodônticos e comprometendo a qualidade da obturação do canal radicular (ECONOMIDES et al., 1999).

Shahravan et al. (2007), avaliaram o efeito da smear layer na qualidade do selamento da obturação dos canais radiculares em uma revisão sistemática e metaanálise de artigos publicados entre os anos de 1975 e 2005. Concluíram que a sua remoção melhora a qualidade de selamento da obturação endodôntica, com consequente diminuição de infiltração de fluidos tissulares. Salientaram que a técnica de obturação ou o cimento endodôntico utilizado não demonstraram efeitos significativos.

Fica evidente, por meio da literatura, que as chances de sucesso da terapêutica endodôntica aumentam, quando a camada de smear é removida do canal radicular. Instrumentos ultrasônicos, lasers, e agentes quelantes têm sido utilizados tanto para a remoção química e mecânica da smear layer, quanto da smear plug (TORABINEJAD et al., 2003). A procura por uma solução irrigante comum, simples e de baixo custo, que promova a sua eliminação das paredes dentinárias tem sido alvo de pesquisa de vários estudos (ESTRELA et al., 2007, PRADO et al., 2011; KHEDMAT; SHOKOUHINEJAD, 2008; CARVALHO et al., 2008).

Diferentes autores têm investigado a eficácia do EDTA associado à variadas concentrações de hipoclorito de sódio para a remoção da smear layer. Esta combinação é considerada atualmente o método mais eficaz para essa finalidade (MARQUES et al., 2006; ESTRELA et al., 2007; SPANÓ et al., 2009).

O EDTA constitui-se, portanto, a solução quelante mais utilizada na Endodontia. A sua reação com os íons cálcio da dentina resulta em quelato de cálcio, proporcionando descalcificação na estrutura dentinária em uma profundidade aproximada de 20 a $30 \mu \mathrm{m}$ em 5 minutos (VIOLICH; CHANDLER, 2010). 
Alguns dos atuais agentes quelantes acarretam sérios riscos ao meio ambiente, incluindo o EDTA, por não serem biodegradáveis. Eles promovem a depleção de metais necessários ao metabolismo de alguns microorganismos, promovendo um desequilíbrio na cadeia alimentar. Podem também se ligar a metais pesados e serem ingeridos pelos seres humanos, causando intoxicação. A avaliação do impacto sobre o meio ambiente decorrente de emissões dos agentes quelantes é realizada por meio da análise de águas de rios e esgotos (JAWORSKA; SCHOWANEK; FEIJTEL, 1999). A preocupação com o meio ambiente tem levado os pesquisadores a procurar substâncias alternativas ao EDTA, uma vez que a concentração desse composto tem aumentado consideravelmente nos rios e lagos. O EDTA é considerado um poluente visto que este elemento não é encontrado originalmente na natureza (SPANÓ et al., 2009).

A busca por soluções mais biocompatíveis que o EDTA, com o objetivo de minimizar a agressão aos tecidos periapicais tem se mostrado cada vez mais frequente nos estudos. Como exemplo, podem-se destacar alguns ácidos fracos, como os ácidos cítrico e lático e o vinagre de maçã (HAZNEDAROGLU, 2003; SPANÓ et al., 2009; PRADO et al., 2011). Avanços na área odontológica têm sido proporcionados pelo desenvolvimento científico no setor de biomateriais e dispositivos biomédicos. Em particular, as pesquisas focalizam-se no desenvolvimento de novas biomacromoléculas e materiais biocompatíveis para uso clínico odontológico (WU et al., 2008).

A quitosana é um polissacarídeo natural o qual tem atraído grande atenção dos pesquisadores no âmbito odontológico devido às suas propriedades de biocompatibilidade, biodegradabilidade, bioadesão e atoxidade diante do organismo humano (SENEL; KAS; SQUIER, 2000; AKNCBAY; SENEL; AY, 2007). Essa substância é aviada por desacetilação da quitina, a qual é obtida a partir de cascas de caranguejo e camarão (KURITA, 1998). Sendo uma substância abundante na natureza e com baixo custo para sua produção, torna-se ecologicamente interessante seu aproveitamento para diversas finalidades (PETER, 1995). Tem sido amplamente utilizada nas diversas áreas: farmacêutica e médica (efeito antibacteriano, agente antitumor, carreador para drogas, acelerador de cicatrização de feridas), biotecnologia (carreador para enzimas e células, resina para cromatografia, matéria para membranas), meio ambiente (tratamento de água), agricultura (preparação de sementes, ativador de células de plantas, atividade 
antimicrobiana para patógenos de plantas), cosméticos e alimentação (acelerador de absorção de ferro e cálcio, fonte de fibras) (JEON; SHAHID; KIN, 2000).

Biologicamente, a quitosana absorve ou liga-se às gorduras, com isso, induz redução de peso. Em adição, ajuda no controle do colesterol, acelera a cicatrização de tecidos conjuntivos, facilita a hemostasia (KLOKKEVOLD et al., 1991) e induz formação óssea (MUZZARELLI et al., 1994; PARK et al., 2008).

Na periodontia, o uso da quitosana em gel bem como sua associação à matriz de osso desmineralizado ou à membrana colágena tem se mostrado efetivos como auxiliares na regeneração periodontal em defeitos intraósseos (PARK et al., 2003; BOYNUEGRI et al. 2009). Também foi avaliado o potencial do polímero em auxiliar o combate à Candida albicans (SENEL et al., 2000). Sua utilização como veículo junto à pasta de hidróxido de cálcio, como medicação intracanal, promove a liberação prolongada de íons cálcio (BALLAL et al., 2010).

A quitosana possui alta capacidade quelante por vários íons metálicos (incluindo $\mathrm{Ni}^{2+} \mathrm{Zn}^{2+}, \mathrm{Co}^{2+}, \mathrm{Fe}^{2+}, \mathrm{Mg}^{2+}$ e $\mathrm{Cu}^{2+}$ ) em condições ácidas, e tem sido amplamente aplicado para remoção ou recuperação dos íons metálicos em diferentes áreas da indústria (KURITA, 1998).

Diante das propriedades da quitosana que proporcionam versatilidade de aplicação na Odontologia, sua capacidade quelante sobre as paredes dos canais radiculares ainda não foi investigada na literatura. Dessa forma, torna-se interessante pesquisar sobre essa propriedade, avaliando o desempenho da quitosana em remover a smear layer, e assim verificar a possibilidade do uso como substância auxilar na terapêutica endodôntica. 


\section{REVISTA DA LITERATURA}

Com intuito de organizar os assuntos e facilitar a leitura, o presente capítulo foi dividido em dois subitens: soluções irrigantes e auxiliares; quitosana: propriedades e aplicações.

\section{Soluções irrigantes e auxiliares}

Orstavik e Haapasalo (1990) avaliaram o efeito de diferentes soluções irrigantes e curativos endodônticos em amostras de dentina bovina infectadas experimentalmente com Enterococcus faecalis, Streptococcus sanguis, Escherichia coli ou Pseudomonas aeruginosa. Foram preparados cilindros de dentina, os quais foram padronizados e limpos por tratamento ultrassônico, EDTA e hipoclorito de sódio. Os espécimes foram infectados por períodos de até 14 dias. A avaliação do grau de infecção nos túbulos ocorreu por meio do método Brown e Brenn, microscopia eletrônica de varredura (MEV) e cultura de pó de dentina. Medicações endodônticas foram aplicadas às amostras infectadas para comparar a capacidade 
antibacteriana. Os resultados mostraram que o paramonoclorofenol canforado foi mais eficiente que o Calasept ${ }^{\circledR}$. Dentre as soluções estudadas, o iodeto de potássio apresentou-se mais eficiente que o hipoclorito de sódio e clorexidina. Os autores salientaram que a presença de smear layer retardou, mas não eliminou o efeito das medicações.

Abbot (1991) pontuou os fatores que afetam o sucesso endodôntico e discutiu os métodos utilizados para reconhecer e evitar possíveis falhas. Segundo o pesquisador, muitos fatores podem contribuir para o insucesso da terapia endodôntica, mas o principal está associado à presença de bactérias. Por fim, chama a atenção para o fato de que as falhas no tratamento podem ser reconhecidas por meio dos exames clínicos e radiográficos, sendo passíveis de prevenção por meio de cuidadosa seleção do caso.

Sen, Wesselink e Türkün (1995) relataram que durante a instrumentação endodôntica há formação de uma camada composta de dentina, restos de tecido pulpar e processos odontoblásticos, além de bactérias. Esta camada, denominada smear layer, tem aparência amorfa, irregular e granular sob o microscópio eletrônico de varredura. Os autores complementam que a smear layer atua como uma barreira física e interfere na aderência e penetração de cimentos nos túbulos dentinários, podendo afetar a eficiência da vedação da obturação do canal radicular.

O efeito da camada de smear na microinfiltração apical após obturação dos canais radiculares foi avaliada por Economides et al. (1999). Cento e quatro dentes humanos extraídos foram distribuídos em quatro grupos tratados da seguinte forma: GA1- a smear layer foi mantida e os canais foram obturados com guta-percha e cimento Roth 811; GA2- manutenção da smear layer e canais obturados com gutapercha e AH26; GB1- a smear layer foi removida e os canais obturados com gutapercha e Roth 811; GB2- remoção da smear layer e canais obturados com gutapercha e AH26. A microinfiltração foi mensurada pelo método eletroquímico. Paralelamente, parte da amostra foi examinada por microscópio eletrônico de varredura. Os resultados indicaram que a remoção da smear layer resultou em uma redução estatisticamente significativa dos valores de microinfiltração em grupos obturados com AH26. A presença ou não da smear layer não teve efeito significativo sobre a capacidade de selamento do Roth 811.

Jaworska, Schowanek e Feijtel (1999) preocupados com o meio ambiente, sugeriram o uso de um agente quelante e biodegradável, o $[\mathrm{S}, \mathrm{S}]$ etileno-diamino 
disuccinato ([S,S]-EDDS), como auxiliar no tratamento de esgoto. Os autores enfatizaram que a propriedade deste composto que o distingue de outros quelantes é a sua alta capacidade de biodegradação (sem metabólitos persistentes) e baixa toxicidade para peixes e alguns crustáceos. Concluíram que o uso deste composto, nos compartimentos ambientais observados, não apresentou índices preocupantes.

A ação da solução de EDTA na remoção da smear layer e seu efeito na estrutura dentinária foram avaliados por Çalt e Serper (2002). Seis dentes unirradiculares foram instrumentados, os quais tiveram, posteriormente, os terços cervical e médio cortados e desprezados. A porção referente ao terço médio foi cortada longitudinalmente em dois segmentos iguais. Utilizaram-se $10 \mathrm{~mL}$ de EDTA $17 \%$ para irrigação das metades pertencentes à mesma raiz, durante 1 e 10 minutos, respectivamente. Todos os dentes tiveram irrigação final com $10 \mathrm{~mL}$ de hipoclorito de sódio $5 \%$. Os resultados evidenciaram que com apenas 1 minuto de ação, a solução de EDTA mostrou-se eficiente na remoção da smear layer. Entretanto, a aplicação da solução de EDTA durante 10 minutos, causou erosão excessiva da dentina peritubular e intertubular. Os pesquisadores sugeriram que este procedimento não deveria ser prolongado por mais de um minuto durante a terapêutica endodôntica.

Pécora et al. (2002), com objetivo de reduzir o índice de fratura de instrumentos de níquel titânio utilizados com sistemas mecanizados, preconizaram o uso da técnica Free Tip Preparation. Essa técnica tem como princípio o preparo do canal radicular de forma que a ponta do instrumento não toque as paredes dentinárias, na maioria das vezes, servindo apenas como guia e diminuindo, assim, a possibilidade de fratura.

Torabinejad et al. (2002) fizeram uma revisão bibliográfica com ênfase nas implicações clínicas da smear layer na endodontia. Segundo os autores, está bem estabelecido que a instrumentação do canal radicular promove a formação da smear layer, a qual recobre as superfícies das paredes dentinárias. Observaram que há vários métodos utilizados para sua remoção, no entanto, a manutenção ou não dessa camada, ainda é bastante discutível no âmbito científico.

Haznedaroğlu (2003) estudou, por meio da MEV, a eficiência do ácido cítrico em diferentes concentrações e pH, na remoção da smear layer da superfície dentinária. Utilizaram-se 50 caninos superiores extraídos, os quais foram irrigados com hipoclorito de sódio $2,5 \%$ durante a instrumentação. As soluções de ácido 
cítrico foram preparadas nas concentrações de 50\%, 25\%, 10\% e 5\%. Concluída a instrumentação, os terços cervical e apical da raiz foram removidos. A porção média foi seccionada longitudinalmente em dois segmentos, sendo um imerso em ácido cítrico com pH original e o outro, no mesmo ácido, porém com pH 6, ambos por 2 minutos. Em seguida, as amostras foram colocadas em recipientes contendo hipoclorito de sódio 2,5\% e água destilada, por 2 e 1 minuto respectivamente. Os resultados mostraram que as soluções com baixas concentrações e baixo pH removeram a smear layer mais eficientemente que as soluções de $\mathrm{pH}$ elevado $(p<0,05)$. Não houve diferença significante nos grupos em que as concentrações do ácido eram altas, independentemente do $\mathrm{pH}$. Entretanto, ocorreu maior destruição de dentina peritubular na utilização das soluções de altas concentrações e pH baixo.

Hülsmann, Heckendorff e Lennon (2003) realizaram uma revisão da literatura sobre as substâncias quelantes utilizadas na Odontologia, bem como o emprego e função dos quelantes na Endodontia. Verificaram que as soluções quelantes apresentam a capacidade de desmineralizar a dentina, facilitando a ação dos instrumentos em canais atrésicos, reduzem a microdureza, aumentam a permeabilidade dentinária, facilitando a ação da medicação intracanal e removem smear layer.

Torabinejad et al. (2003) avaliaram, por meio da MEV, a capacidade de limpeza do MTAD, uma substância composta de isômero de tetraciclina, ácido e detergente, como um irrigante final na superfície dos canais radiculares. Quarenta e oito dentes humanos unirradiculares receberam, após a biomecânica, $5 \mathrm{~mL}$ de uma das seguintes soluções: água destilada, hipoclorito de sódio $5,25 \%$, EDTA $17 \%$ e MTAD. A quantidade de smear layer, assim como o grau de erosão sobre a superfície dos três terços do canal radicular foi avaliado. Os resultados mostraram que MTAD foi eficiente na remoção da smear layer, não alterando a estrutura dos túbulos dentinários.

Scelza et al. (2004) estudaram a capacidade de remoção da smear layer após o uso de diferentes soluções irrigantes variando-se o tempo de irrigação. Noventa dentes caninos foram distribuídos em 9 grupos, conforme a solução empregada na irrigação final. Utilizaram-se $20 \mathrm{~mL}$ das soluções de EDTA-T, EDTA $17 \%$ e ácido cítrico $10 \%$ no período de 3, 10 e 15 minutos. Após os tratamentos os espécimes foram analisados por meio de MEV. Os resultados apontaram que o ácido cítrico $10 \%$ por 3 minutos foi significantemente melhor que nos tempos de 10 e 15 minutos 
de irrigação. No grupo do EDTA $17 \%$ a irrigação por 3 minutos também foi mais eficiente que a de 15 minutos, apresentando maior quantidade de canalículos abertos. Não houve diferença significante entre os 3 períodos no grupo do EDTA-T. Os pesquisadores concluíram que as soluções avaliadas foram eficientes em um curto intervalo de tempo não melhorando o efeito com o aumento do tempo.

Slutzky-Goldberg et al. (2004) estudaram o efeito do hipoclorito de sódio sobre a microdureza da dentina radicular. Quarenta e duas raízes de incisivos bovinos foram distribuídas em 6 grupos, variando-se a concentração da solução irrigante ( $\mathrm{NaOCl}$ 2,5 e 6\%) e o período de irrigação (5, 10 e 20 minutos). No grupo controle utilizou-se solução salina. As raízes foram cortadas transversalmente obtendo-se assim, discos de dentina, os quais foram lixados, polidos e levados a um aparelho de microdureza Vickers. As mensurações foram realizadas a $500 \mu \mathrm{m}, 1000$ $\mu \mathrm{m}$ e $1500 \mu \mathrm{m}$ da luz do canal radicular. Os resultados apontaram diminuição da microdureza em todas as distâncias analisadas para ambas concentrações, no entanto, o $\mathrm{NaOCl} 6 \%$ a $500 \mu \mathrm{m}$ promoveu uma redução significantemente maior que a $2,5 \%$.

Kokkas et al. (2004) avaliaram, por meio da MEV, o efeito da smear layer na capacidade de penetração de três cimentos endodônticos através dos túbulos dentinários. Após o preparo químico-mecânico de 64 dentes unirradiculares, os espécimes foram distribuídos em dois grupos: GA- a camada de smear permaneceu intacta; GB- remoção completa da smear layer. Duas raízes de cada grupo foram utilizadas como controle. Os grupos foram redistribuídos de acordo com o cimento obturador a ser utilizado: AH Plus, Apexit e Roth 811. Os resultados revelaram que a smear layer agiu como um selante dos túbulos dentinários, impedindo a penetração dos cimentos, enquanto que sua remoção permitiu a penetração de todos os cimentos numa profundidade variável.

Marques et al. (2006) verificaram a capacidade de remoção da smear layer e de íons cálcio da dentina radicular após irrigação com 3 diferentes soluções quelantes. Dezesseis dentes caninos foram instrumentados pela técnica Step Back. A cada troca de lima utilizou-se $1 \mathrm{~mL}$ de solução quelante conforme os grupos: G1EDTAC 17\%; G2- CDTA 17\%; G3- EGTA 17\%. Ao final do preparo biomecânico foram coletados $8 \mathrm{~mL}$ de cada solução, os quais foram levados ao espectrofotômetro de absorção atômica para análise da quantidade de íons cálcio presente. As raízes foram seccionadas longitudinalmente e preparadas para avaliação em MEV. Os 
autores observaram que o EDTAC e CDTA removeram a smear layer e íons cálcio da dentina de forma mais eficiente que a solução de EGTA. Em relação à limpeza não houve diferença entre os terços analisados.

Estrela et al. (2007) pesquisaram, por meio da MEV, a capacidade de limpeza das paredes dentinárias após irrigação com diferentes soluções. Foram avaliadas as soluções de clorexidina, vinagre de maçã e hipoclorito de sódio associados ou não ao EDTA. Os autores verificaram que a combinação de todas as soluções com EDTA aumentou significantemente a capacidade de remoção da camada de smear, e que o melhor resultado foi obtido com a associação com o vinagre de maçã.

Shahravan et al. (2007) realizaram uma revisão sistemática e meta-análise com enfoque do efeito da smear layer na qualidade da obturação dos canais radiculares. Os autores verificaram artigos publicados entre os anos de 1975 e 2005. Concluíram que a remoção da smear layer melhora a qualidade do selamento endodôntico, com consequente diminuição da infiltração de fluidos.

Papagianni (2007) enfatiza os aspectos da bioquímica de fermentação, transporte de membrana e modelo do processo de produção do ácido cítrico por meio do Aspergillus niger. Salientaram que o mecanismo bioquímico pelo qual o Aspergillus niger acumula ácido cítrico continua a atrair o interesse científico, embora a sua produção comercial por fermentação tenha sido estabelecido há décadas.

Carvalho et al. (2008) avaliaram, por meio da MEV, a capacidade de limpeza de diferentes soluções utilizadas para irrigação. Trinta e dois dentes unirradiculares foram distribuídos em 4 grupos $(n=8)$ de acordo com a solução irrigante empregada na biomecânica: G1- NaOCl 2,5\% + EDTA 17\%; G2- Clorexidina Gel 2\% + EDTA 17\%; G3- Canal Plus (associação de EDTA com peróxido de hidrogênio) $+\mathrm{NaOCI}$ 2,5\%; G4- soro + EDTA $17 \%$. Os resultados mostraram grande quantidade de túbulos dentinários abertos no G1 e G3. Em todos os grupos, a limpeza obtida no terço cervical foi melhor que a dos terços apical e médio, com diferença estatística significante no grupo da clorexidina.

Silva et al. (2008) avaliaram, por meio da MEV, a capacidade de remoção da smear layer dos canais radiculares, após irrigação com diferentes substâncias. Trinta dentes unirradiculares foram instrumentados e distribuídos em 3 grupos de acordo com a solução a ser testada: G1- EDTA 14,3\%, G2- SmearClear $^{\circledR}$ e G3- sem irrigação (controle). Foram obtidas fotomicrografias com aumentos de 200x e 750x 
para avaliação da quantidade da smear layer nos terços cervical, médio e apical. Os resultados mostraram que os grupos 1 e 2 removeram a smear layer de forma similar entre si e de forma superior ao grupo 3, com diferença estatisticamente significante $(p<0,01)$.

Khedmat e Shokouhinejad (2008) compararam, por meio da MEV, a eficácia da SmearClear ${ }^{\circledR}$ na remoção da smear layer. Quarenta e nove dentes unirradiculares foram preparados com instrumentos rotatórios de níquel titânio Mtwo. Os dentes foram distribuídos em 4 grupos $(n=12)$ de acordo com o protocolo de irrigação final por 1 min: G1- $\mathrm{NaOCl}$ 5,25\% (controle); G2- Smear Clear; G3- EDTA 17\%; G4ácido cítrico $10 \%$. Os resultados mostraram que as soluções avaliadas limparam o canal radicular de forma semelhante entre si. Em relação aos terços, não houve diferença significante nos grupos do EDTA 17\% e SmearClear. Entretanto, o ácido cítrico $10 \%$ limpou os terços cervical e médio de forma mais eficaz que o apical $(p<0,05)$. Os autores concluíram que as soluções não foram totalmente eficientes na remoção da smear layer, especialmente no terço apical. A adição de um surfactante ao EDTA não resultou em maior eficácia desta substância.

Pérez-Heredia et al. (2008) avaliaram o efeito descalcificante de diferentes soluções irrigantes, por meio da espectrofotometria de absorção atômica. Foram obtidos dois cortes da porção cervical de 10 dentes incisivos humanos. Posteriormente, seccionaram-se os cortes ao meio, totalizando 40 espécimes, os quais foram distribuídos de acordo com a solução avaliada ( $n=10)$ : G1- EDTA $15 \%$; G2- ácido cítrico 15\%; G3- ácido fosfórico 5\%; e G4- hipoclorito de Sódio 2,5\%. Os corpos-de-prova foram tratados em diferentes períodos de tempo $(5,10$ e 15 minutos). Os espécimes permaneceram submersos nas soluções e, a cada 5 minutos, $5 \mathrm{~mL}$ da solução irrigante foi extraída para ser analisada. Os resultados evidenciaram que, nos três períodos de tempo, o EDTA $15 \%$ e ácido cítrico 15\% foram similares na capacidade descalcificante e com resultados estatisticamente melhores que o ácido fosfórico $5 \%$. A descalcificação da dentina radicular foi mais acentuada nos primeiros 5 minutos em todos os grupos.

Reis et al. (2008) pesquisaram, por meio de MEV e microscopia óptica Cosite, o efeito de altas concentrações do ácido cítrico na dentina humana. Neste experimento foram utilizados 16 molares superiores, os quais tiveram suas coroas seccionadas e desprezadas. A porção cervical das raízes foi exposta e submetida ao tratamento com ácido cítrico 1, 5 e 10\% e EDTA 17\%. O período de observação dos 
espécimes variou de 15 a 300 segundos. Os autores verificaram que as soluções de ácido cítrico apresentaram os maiores efeitos quelantes, sendo que quanto maior a concentração, maior a desmineralização. As soluções de ácido cítrico 5 e 10\% promoveram efeito erosivo na dentina inter e peritubular, após 60 segundos de ação.

Mahran e Aboel-Fotouh (2008) realizaram um estudo comparativo do desgaste cervical promovido por diferentes instrumentos, como também, quantificaram a dentina excisada durante a biomecânica. Canais mésio-vestibulares de 45 molares inferiores foram distribuídos de acordo com o instrumento empregados: G1- ProTaper; G2- Shaper Hero; e G3- associação de brocas Gates e limas manuais Flex-R. A espessura cervical da dentina e o volume de material excisado do canal radicular foram mensurados antes e após a instrumentação por meio da tomografia computadorizada. Os resultados indicaram que as limas ProTaper removeram significativamente menores quantidades de dentina na porção cervical da parede distal (zona crítica) em relação à HeroShaper e Brocas Gates Glidden $(p<0,05)$. Entretanto, o total de estrutura dentinária removida durante a instrumentação foi significativamente maior com o sistema ProTaper $(p<0,05)$.

Spanó et al. (2009) avaliaram a capacidade de remoção da smear layer promovida pela ação de agentes quelantes e desmineralizantes e quantificaram a concentração de íons cálcio presentes nas soluções após a utilização. Quarenta e dois incisivos centrais superiores foram instrumentados e a cada troca de instrumento os espécimes receberam $2 \mathrm{~mL}$ de $\mathrm{NaOCl} 1 \%$. Posteriormente, os dentes foram distribuídos em 7 grupos ( $n=6)$, conforme a irrigação final estabelecida: G1EDTA 15\%; G2 - ácido cítrico 10\%; G3- citrato de sódio 10\%; G4- vinagre de maçã; G5 - ácido acético 5\%; G6 - ácido málico 5\%; G7- sem irrigação final (controle). Durante a irrigação, as soluções foram simultaneamente coletas, após extravasamento apical, e encaminhadas à análise espectrométrica. Os autores verificaram que o EDTA $15 \%$ e o ácido cítrico 10\% removeram a smear layer de forma semelhante entre si. As demais soluções não foram eficientes para esta finalidade. A maior quantidade de íons cálcio removidos foi observada no grupo do EDTA $15 \%$, seguido do ácido cítrico $10 \%$. O citrato de sódio $10 \%$ apresentou as menores quantidades do ín.

Mancini et al. (2009) pesquisaram, comparativamente, a capacidade de remoção da smear layer e o grau de erosão provocado no terço apical, após irrigação com 3 soluções auxiliares quelantes. Noventa e seis dentes unirradiculares 
foram instrumentados empregando-se o sistema rotatório $\mathrm{GT}^{\circledR}$ e irrigados com $2 \mathrm{~mL}$ de $\mathrm{NaOCl} 5,25 \%$ a cada troca de lima. Os espécimes, posteriormente, foram distribuídos em 4 grupos de acordo com a solução quelante utilizada na irrigação final: G1- Bio-pure MTAD; G2- EDTA 17\%; G3- ácido cítrico 42\%. Foi utilizado $1 \mathrm{~mL}$ de cada solução auxiliar por 1 minuto seguido de $3 \mathrm{~mL}$ de $\mathrm{NaOCl} 5,25 \%$ e mais $5 \mathrm{~mL}$ de água destilada. Em relação à limpeza, a análise estatística mostrou haver diferença significante entre os grupos do Bio-pure MTAD e EDTA em relação ao ácido cítrico, o qual foi similar ao grupo do $\mathrm{NaOCl}$ (controle). Os autores salientaram que o protocolo empregado no trabalho não foi suficiente para promover a limpeza adequada do terço apical, dessa forma, não foi possível avaliar o grau de erosão.

Şen, Erturk e Pişkin (2009) verificaram, por meio de MEV, a capacidade de limpeza e a erosão decorrente do uso do EDTA em diferentes concentrações na superfície da dentina radicular. Quarenta dentes unirradiculares foram preparados pela técnica Step Back e irrigados com $\mathrm{NaOCl} 2,5 \%$ a cada troca de instrumento. Os espécimes foram distribuídos em 4 grupos de acordo com a solução quelante utilizada como irrigação final: G1- EDTA $15 \%$; G2- EDTA 10\%; G3- EDTA 5\%; G4EDTA $1 \%$. Utilizaram-se $5 \mathrm{~mL}$ de cada concentração de EDTA por 1 minuto. Os resultados mostraram que todas as soluções limparam, de forma estatisticamente semelhante, as paredes do canal radicular. O terço cervical mostrou-se com menor quantidade de smear layer que o apical. As soluções de EDTA 15, 10 e $5 \%$ apresentaram erosões similares entre si, não havendo diferença entre os terços da raiz. Os autores concluíram que o EDTA em pequena concentração pode ser recomendado clinicamente, uma vez que impede a erosão excessiva da parede dentinária.

Mai et al. (2010) avaliaram, por meio da microscopia eletrônica de transmissão (MET), o possível efeito erosivo do $\mathrm{NaOCl} 5,25 \%$ associado ao EDTA $17 \%$ nas paredes dentinárias. Trinta terceiros molares humanos foram utilizados para obtenção de discos de dentina dos terços médio e cervical. Foram empregados dois protocolos de irrigação, simulando tratamentos rápidos e tratamentos complexos, nos quais ocorre maior tempo de contato da solução com o tecido dentinário: $\mathrm{G} 1-\mathrm{NaOCl} 5,25 \%$ por 10 min. e EDTA $17 \%$ como irrigante final por 2 min.; G2- $\mathrm{NaOCl} 5,25 \%$ por $60 \mathrm{~min}$. e EDTA $17 \%$ por $2 \mathrm{~min}$. Os resultados mostraram que para os dois protocolos de irrigação com $\mathrm{NaOCl} 5,25 \%$, a irrigação final de EDTA resultou em desmineralização similar com $0,5 \mu \mathrm{m}$ de espessura. 
Entretanto, a imersão em 60 minutos resultou em extensa erosão na superfície radicular. Os autores concluíram que a aparente agressividade do EDTA 17\% em provocar erosão nas paredes dos canais radiculares é, na verdade, atribuída ao uso prolongado de $\mathrm{NaOCI} 5,25 \%$, podendo tornar os dentes tratados endodonticamente mais susceptíveis à fratura vertical.

Mello et al. (2010) compararam, por meio da MEV, a capacidade de remoção da smear layer após utilização de duas técnicas de irrigação com EDTA 17\%. Sessenta dentes humanos unirradiculares foram instrumentados e distribuídos conforme o protocolo de irrigação: G1- irrigação contínua com 5 mL EDTA 17\%, por 3 minutos; G2- irrigação inicial de $1 \mathrm{~mL}$ de EDTA 17\% por 6 segundos, seguida da inundação do canal com EDTA 17\%, por 2 minutos e meio, mais irrigação final com $4 \mathrm{~mL}$ da mesma solução, por 24 segundos. Os autores verificaram que o grupo com irrigação contínua apresentou maior superfície livre de smear layer quando comparado ao outro grupo. Conclui-se que a irrigação contínua de $5 \mathrm{~mL}$ de EDTA $17 \%$ por 3 minutos pode remover de forma eficiente a smear layer.

Violich e Chandler (2010) realizaram, por meio de 408 trabalhos divulgados no PubMed, uma revisão literária focando a relevância da smear layer para a Endodontia. Os autores afirmaram que a remoção da smear layer reforça a desinfecção do canal radicular e que, dentre os métodos atuais empregados para essa finalidade (química, ultrassom e técnicas utilizando laser), nenhum é totalmente eficaz. A maioria dos trabalhos recomenda o uso do EDTA alternado com hipoclorito de sódio para a limpeza do canal.

Zhang et al. (2010) avaliaram, por meio da MEV e MET, a capacidade de remoção da porção orgânica da dentina e o grau de erosão nas paredes dos canais radiculares após o uso de $\mathrm{NaOCl}$ seguido de EDTA. Dentina em pó foi imersa em $\mathrm{NaOCl} 5,25 \%$ ou $1,3 \%$ em diferentes tempos $(10,20,30,60,120,180$ e 240 minutos) seguido de irrigação com EDTA $17 \%$ por 2 min. Antes e após o uso do EDTA $17 \%$, a dentina em pó foi examinada por meio da espectroscopia (ATR-FT-IR) para verificação da perda de componentes orgânicos e inorgânicos. Os resultados mostraram que o uso de $\mathrm{NaOCl} 5,25 \%$ ocasionou maiores alterações na estrutura colágena, independentemente da irrigação posterior com EDTA 17\%. A erosão das paredes dentinárias foi observada apenas no grupo do $\mathrm{NaOCl} 5,25 \%$ seguido de EDTA $17 \%$. A erosão estendeu-se 10-15 micrometros abaixo da superfície da 
dentina após o uso de $\mathrm{NaOCl} 5,25 \%$ por 20 min. Os autores concluíram que o efeito destrutivo superficial do $\mathrm{NaOCl}$ é irreversível e independe do uso posterior de EDTA.

Prado et al. (2011) verificaram, por meio da MEV, a capacidade de remoção da smear layer após o uso do ácido fosfórico 37\% (solução e gel), EDTA 17\% e ácido cítrico $10 \%$. Após a instrumentação de 52 caninos humanos superiores, os espécimes foram irrigados com água destilada e distribuídos em grupos, conforme as soluções descritas. O tempo de irrigação com os agentes irrigantes variou em 30 segundos, 1 e 3 minutos. A MEV forneceu 3 fotomicrografias (2000x) de cada amostra, para avaliação dos terços apical, médio e cervical. Os resultados mostraram que nenhuma das substâncias empregadas foi eficiente na remoção da smear layer no período de 30 segundos. No período de 1 minuto a solução de ácido fosfórico apresentou melhores resultados que as demais. No período de 3 minutos todas as substâncias apresentaram bom desempenho nos terços cervical e médio. Os autores concluíram que a solução de ácido fosfórico apresenta-se como um agente promissor para remoção da smear layer.

\section{Quitosana: propriedades e aplicações}

Em relação ao mecanismo de quelação da quitosana, Blair e Ho (1981) e Focher et al. (1986), sustentam a teoria de que dois ou mais grupos amino da cadeia de quitosana ligam-se ao mesmo íon metálico (modelo da ponte). Blair e Ho (1981) avaliaram a adsorção e difusão de íons cobre e de um corante, utilizando membranas de quitosana contendo diferentes quantidades de íons cobre quelatado. Os resultados indicaram que aumentando o teor de cobre sobre a membrana, diminui-se a taxa de difusão de íons através da membrana.

Domard (1987) e Piron e Domard (1998) defendem a teoria de que apenas um grupo amino da estrutura da quitosana é envolvido na ligação entre a substância e o metal. Piron e Domard (1998) avaliaram, por meio da espectrofotometria, o mecanismo de interação que ocorre entre o quelante e íons de urânio. Os resultados mostraram que a saturação do polímero por íons de urânio ocorreu na proporção de $2: 1$, devido às propriedades intrínsecas da quitosana. Os autores observaram a formação de um único tipo de complexo caracterizado por ligações coordenadas dos grupos amino da quitosana com íons urânio. 
Onsøyen e Skaugrud (1990) relataram que a quitosana é um polímero policatiônico natural com propriedades valiosas. Possui várias aplicações como no tratamento de águas residuais para a remoção de metais pesados e isótopos de rádio; no tratamento de águas para recuperação de metais valiosos; purificação de água potável; liberação controlada de metais essenciais para o crescimento de plantas, na agricultura; e na indústria alimentícia, na melhora do sabor de alimentos cozidos e requentados, por meio da quelação de ferro. Os autores salientam que as interações dos metais com a quitosana são complexas, apresentando provavelmente, processos simultâneos de adsorção, troca iônica e quelação. Por fim, chamam a atenção para fato de que o grau de polimerização, a desacetilação e a distribuição dos grupos acetil na cadeia do polímero é de importância crucial para definir as características de interação entre quitosana e metal.

Klokkevold et al. (1991) avaliaram o efeito hemostático da quitosana em ferimentos de coelhos, por meio dos tempos de sangramento e de coagulação. Foram realizadas duas incisões ( $15 \times 2$ milímetros) nas línguas dos animais, sendo uma tratada com um preparado à base de quitosana e a outra sem medicação (controle). Os tempos de sangramento e coagulação foram verificados em três momentos: no pré-operatório, pós-operatório e antes do sacrifício dos animais. Os resultados revelaram que as incisões que receberam o composto com quitosana apresentaram uma hemostasia $32 \%$ maior que o grupo controle.

Muzzarelli et al. (1994) verificaram o efeito da quitosana modificada em defeitos ósseos no côndilo femural de ovelhas. Os defeitos foram confeccionados cirurgicamente (7 milimetros de diâmetro) e tratados de acordo com os grupos propostos: com e sem quitosana. Os resultados mostraram que no período de 40 dias após a cirurgia, o grupo que recebeu o tratamento com a substância apresentou neoformação óssea. O novo tecido formado mostrou-se com aspecto de um nódulo mineralizado com componente fibroso, na região central, e na região periférica, com estrutura trabecular. No grupo controle, nenhum sinal de formação óssea ou processo de reparo foram observados. Os autores concluíram que a quitosana tem um forte potencial osteoindutor.

Peter (1995) realizou uma revisão literária sobre as propriedades dos polissacarídeos naturais quitina e quitosana. Os pesquisadores ressaltaram que as características proeminentes das propriedades químicas e mecânicas desses materiais, oferecem inúmeras aplicações, ainda pouco exploradas nas áreas da 
tecnologia, química, medicina e agricultura. Os derivados de quitina e quitosana podem ser obtidos por meio de reações dos grupos hidroxi e amino com reagentes adequados. Vários tipos de géis, membranas e fibras, incluindo materiais policatiônicos e solúveis em água, podem ser formados. Os autores enfatizam, por fim, que a produção de quitina e quitosana, a partir de resíduos de caranguejo, são realizadas por meio de processos que não prejudicam o meio ambiente.

Kurita (1998) avaliaram a afinidade de derivados organossolúveis da quitina por solventes, sua atividade antimicrobiana, assim como a susceptibilidade à lisozima. Vários grupamentos podem ser introduzidos às estruturas químicas da quitina e quitosana para obtenção de compostos não naturais, de forma a melhorar a efetividade de suas propriedades. Os derivados de quitina resultantes revelaram que $\beta$-quitina apresentou-se com melhor desempenho que a usual $\alpha$-quitina.

Guibal, Milot e Roussy (2000) avaliaram o mecanismo de quelação de molibidênio pela quitosana, e os possíveis fatores que interferem nesse processo. Os autores concluíram que a interação entre o quelante e a substância caracterizase pela "ancoragem" dos íons molibidênio nos grupos amino da quitosana. Associado à esse processo ocorre o mecanismo de troca iônica. Verificaram que vários grupos amino podem também reagir com o mesmo grupo de molibidênio. $O$ tipo de interação depende do íon metálico, de sua estrutura química e do $\mathrm{pH}$ da solução.

Senel, Kas e Squier (2000) relataram que a quitosana é um polissacarídeo natural que tem atraído grande atenção dos pesquisadores no âmbito odontológico devido às suas propriedades de biocompatibilidade, biodegradabilidade, bioadesão e atoxidade diante do organismo humano.

Senel et al. (2000) avaliaram, in vitro, a atividade antifúngica da quitosana associada ou não à clorexidina, assim como o tempo de liberação dessas substância na cavidade oral. Foram preparados géis e membranas de quitosana com concentrações de 1 e $2 \%$ contendo clorexidina 0,1 ou $0,2 \%$. Os resultados evidenciaram que a liberação prolongada foi observada nas formulações em membrana e a maior atividade antifúngica foi obtida com gel de quitosana $2 \%$ contendo clorexidina $0,1 \%$.

Segundo Jeon, Shahide e Kin (2000), a quitosana possui várias propriedades funcionais, as quais têm atraído grande interesse de pesquisadores, visto suas atividades biológicas e potenciais aplicações nas indústrias alimentar, farmacêutica, 
agrícola e ambiental. Muitos artigos científicos destacam a quitosana como uma fonte potencial de materiais bioativos, sendo utilizados nas áreas farmacêutica e médica (efeito antibacteriano, agente anti-tumor, carreador para drogas, acelerador de cicatrização de feridas), na biotecnologia (carreador para enzimas e células, resina para cromatografia, matéria para membranas), no meio ambiente (tratamento de água), na agricultura (preparação de sementes, ativador de células de plantas, atividade antimicrobiana para patógenos de plantas), e no setor de cosméticos e alimentação (acelerador de absorção de ferro e cálcio, fonte de fibras).

Rhazi et al. (2002) avaliaram, por meio de diferentes técnicas, a influência da natureza do íon metálico no processo de quelação com a quitosana. Os resultados mostraram que o polímero apresentou seletividade de acordo com o íon metálico na seguinte sequência de afinidade: $\mathrm{Cu}$ (II) $\geq \mathrm{Hg}$ (II) $>\mathrm{Zn}$ (II) $>\mathrm{Cd}$ (II) $>\mathrm{Ni}$ (II) $>\mathrm{Co}$ (II), $\mathrm{Ca}$ (II) $>\mathrm{Eu}$ (III) $\geq \mathrm{Nd}$ (III) $>\operatorname{Pr}$ (III). Os autores salientaram que a seletividade parece não apresentar relação com o tamanho e dureza dos íons considerados, independentemente da forma de apresentação da quitosana (filme, pó ou solução). Os estudiosos observaram que em função da capacidade quelante seletiva da quitosana, a mesma pode ser utilizada como agente despoluente na recuperação de íns metálicos.

Park et al. (2003) avaliaram, por meio de análise histológica, o comportamento da quitosana associada à esponja de colágeno, no tratamento de defeitos intra-ósseos. Os defeitos foram confeccionados bilateralmente na maxila e mandíbula de cães da raça Beagle. Os grupos foram distribuídos conforme a terapêutica adotada: G1- realizou-se apenas o retalho (controle); G2- utilização de esponja de colágeno associada a um tampão de fosfato; G3- esponja de colágeno associada à quitosana. Os animais foram sacrificados oito semanas após a terapia. Os resultados mostraram diferença estatística na quantidade de migração de epitélio juncional entre $\mathrm{G} 1$ e $\mathrm{G} 3$ ( $p<0,05)$, com o grupo da quitosana apresentando melhor desempenho. Com relação à quantidade de cemento regenerado e reparo ósseo alveolar, observou-se diferença estatisticamente significante entre G3 e os demais grupos, com resultados superiores para G3. Os autores concluíram que a quitosana induziu a regeneração periodontal no tratamento de defeitos intraósseos com inibição apical da migração do epitélio juncional e aumento nas quantidades neoformadas de osso e cemento, 
Akncbay, Senel e Ay (2007) avaliaram o desempenho da quitosana em gel $1 \%$ e em uso associado ao metronidazol $15 \%$ para o tratamento coadjuvante da periodontite crônica. Inicialmente, os pacientes com periodontite crônica receberam terapia de raspagem e alisamento radicular, seguindo-se a distribuição dos grupos de acordo com a medicação empregada: G1- quitosana gel 1\%; G2- quitosana gel $1 \%$ associada ao metronidazol 15\%; G3- sem medicação (grupo controle). Em todos os grupos, foram observadas melhorias significativas nos parâmetros clínicos (profundidade de sondagem, recessão gengival, índice de placa, sangramento gengival) entre o início e 24 semanas após o tratamento. As reduções nos valores da profundidade de sondagem foram $1,21 \mathrm{~mm}$ para o grupo da quitosana, 1,48 $\mathrm{mm}$ para quitosana + metronidazol, e 0,94 mm para o grupo controle. Os autores concluíram que a quitosana isoladamente, bem como associada ao metronidazol foi eficiente no tratamento coadjuvante da periodontite crônica.

Park et al. (2008) avaliaram o efeito de diferentes materiais utilizados no enxerto de defeitos ósseos confeccionados em calvária de 75 ratos. Os animais foram distribuídos em quatro grupos experimentais, conforme o material utilizado: G1- partículas de dentina de porcos; G2- partículas de dentina com sulfato de cálcio hemi-hidratado; G3- partículas de dentina com quitosana; G4- quitosana. Os roedores foram sacrificados com 2, 4 e 8 semanas após a implantação. Os resultados revelaram que todos os grupos experimentais apresentaram maior formação óssea em relação ao controle. Adicionalmente, todos os materiais exibiram maior crescimento ósseo no período de 8 semanas. Particularmente, os autores concluíram que defeitos intraósseos tratados com partículas de dentina em associação à quitosana podem mediar um excelente efeito de neoformação óssea.

Wu et al. (2008) estudaram as propriedades biológicas de uma membrana complexa, composta de ácido hialurônico, colágeno e quitosana. Observaram que a membrana é capaz de induzir crescimento de fibroblastos sob sua superfície, de promover alterações morfológicas das plaquetas durante a coagulação, além de apresentar efeito antimicrobiano contra Escherichia coli e Staphylococcus aureus. Concluíram que a membrana apresentou propriedades efetivas de coagulação, compatibilidade celular, mostrando-se eficiente como agente antibacteriano.

Boynueğri et al. (2009) pesquisaram o efeito da quitosana isoladamente ou associada à membrana colágena ou matriz óssea, no tratamento da periodontite crônica. Após os procedimentos periodontais básico, os pacientes foram distribuídos 
em quatro grupos, de acordo com o tratamento coadjuvante: GA- quitosana gel 1\%; GB- quitosana gel + matriz óssea desmineralizada; GC- quitosana gel + membrana de colágeno; GD- sem complementação (grupo controle). Medidas clínicas e radiográficas foram registrados no início do estudo e nos períodos de 3 e 6 meses após a cirurgia. Os resultados mostraram que, clinicamente, não foram observados diferenças entre os grupos. No entanto, os dados radiográficos revelaram que, com exceção do grupo controle, todos os demais apresentaram neoformação óssea com valores estatisticamente significantes quando comparados aos valores basais. Os autores concluíram que o gel de quitosana utilizado isoladamente ou em associação à matriz óssea desmineralizada ou à membrana colágena foi eficiente como auxiliar para a regeneração óssea.

Ballal et al. (2010) avaliaram, in vitro, o tempo de liberação de íons cálcio e as alterações de $\mathrm{pH}$ provocadas por medicações à base de hidróxido de cálcio com diferentes veículos. Após a biomecânica, os canais radiculares dos espécimes foram preenchidos com pasta de hidróxido de cálcio preparadas com os seguintes veículos: G1- propilenoglicol; G2- polietilenoglicol 6000; G3- quitosana; e G4- goma. Os dentes foram armazenados em frascos de vidro de forma a permitir que apenas o terço apical ficasse imerso em água destilada. Decorridos 30 dias a solução do frasco foi coletada e analisada por meio de espectrofotômetro ultravioleta. Os resultados mostraram que a formulação com quitosana apresentou a maior liberação de íons cálcio em comparação às demais. Os autores chamam a atenção de que a quitosana apresenta-se como um veículo promissor à pasta de hidróxido de cálcio utilizada como medicação intracanal. 


\section{PROPOSIÇÃO}

O presente trabalho tem como objetivo avaliar a capacidade de limpeza das paredes do canal radicular, após irrigação final com soluções quelantes e desmineralizantes, com atenção para os seguintes itens:

1- Avaliar, por meio da microscopia eletrônica de varredura, a capacidade de remoção da smear layer dos terços médio e apical do canal radicular pelas soluções de EDTA $15 \%$, quitosana $0,2 \%$, ácido cítrico $10 \%$ e ácido acético $1 \%$.

2- Quantificar, por meio da espectrometria de absorção atômica com chama, a concentração de íons cálcio presentes nessas soluções após suas utilizações. 



\section{MATERIAL E MÉTODO}

Após a submissão e aprovação do presente projeto pelo Comitê de ética em Pesquisa (CEP) da Faculdade de Odontologia de Ribeirão Preto da Universidade de São Paulo (FORP-USP) (Ref. Processo $n^{\circ}$ 2011.1.205.58.6; CAAE $n^{\circ}$ 0015.0.138.000-11) (Anexo I), foram utilizados 25 dentes caninos superiores cedidos pelo Banco de Dentes da mesma instituição.

Os dentes foram mantidos em solução de timol $0,1 \%$ em geladeira a $9^{\circ} \mathrm{C}$ até o momento do experimento, quando, então, foram lavados em água corrente por 24 horas para remoção do remanescente da solução de timol presente sobre a superfície dos espécimes.

A amostra passou por um processo de seleção pelo qual se observaram os seguintes critérios: presença de canal radicular único e aparentemente reto, rizogênese e apicigênese completas e ausência de calcificação. Os dentes foram examinados clinicamente e na sequência radiografados no sentido próximo-proximal para observação dos critérios adotados. Aqueles que não cumpriram as exigências estabelecidas foram substituídos. 


\section{Preparação dos espécimes}

Inicialmente, realizou-se a cirurgia de acesso com brocas esféricas diamantadas acopladas ao motor de alta rotação (Dabi Atlante, Ribeirão Preto, SP, Brasil) sob refrigeração.

Para o preparo cervical utilizaram-se brocas La Axxess ${ }^{\circledR}$ (Sybronendo Corporation, West Collins, Orange, CA) acionadas por meio de micromotor (Dabi Atlante, Ribeirão Preto, SP, Brasil), na sequência operatória da numeração de 1 a 3 $\left(D_{0}=0,20 ; 0,35 ; 0,45 \mathrm{~mm}\right.$, respectivamente e conicidade de $0,06 \mathrm{~mm} / \mathrm{mm}$ ).

Após o acesso ao canal radicular, concluído, com uma lima tipo $\mathrm{K}$, diâmetro \#10 (Dentsply-Maillefer, Petrópolis, Rio de Janeiro, Brasil) procedeu-se a sondagem do canal e remoção de possíveis remanescentes de tecido pulpar. O instrumento foi introduzido até que sua ponta fosse visualizada no forame apical, quando então, subtraiu-se $1 \mathrm{~mm}$ determinando-se, assim, o comprimento de trabalho (CT).

Terminada esta etapa, determinou-se o diâmetro anatômico (DA), por meio da introdução de instrumentos manuais tipo K (Dentsply-Maillefer, Petrópolis, Rio de Janeiro, Brasil) com diâmetros sucessivos e crescentes até que um deles sofresse resistência ao ser retirado do $\mathrm{CT}$. Os valores referentes ao $\mathrm{CT}$ e DA foram anotados para cada espécime, individualmente.

O preparo biomecânico foi realizado por meio de sistema rotatório contínuo com instrumentos de níquel titânio Quantec ${ }^{\circledR}$ (Sybronendo Corporation, West Collins, Orange, CA, USA) acoplados ao motor elétrico X-Smart (Dentsply-Maillefer, Suíça). A instrumentação do canal radicular, realizada pela técnica "Free Tip Preparation" (PÉCORA et al., 2002), seguiu a ordem crescente de instrumentos, de tal forma que a última lima que percorreu todo o CT apresentava diâmetro correspondente a quatro instrumentos acima daquele que determinou o DA. Dessa forma, assegurouse a remoção de no mínimo $200 \mu \mathrm{m}$ de estrutura dentinária no terço apical.

Durante a etapa de preparação dos espécimes, os mesmos receberam $1 \mathrm{~mL}$ de hipoclorito de sódio $1 \%$ após a abertura coronária, $1 \mathrm{~mL}$ no intervalo entre cada broca utilizada no desgaste compensatório e $1 \mathrm{~mL}$ a cada troca de instrumento utilizado durante a biomecânica. Ao final da instrumentação, irrigou-se o canal com mais $2 \mathrm{~mL}$ de hipoclorito de sódio $1 \%$, totalizando volume aproximado de $10 \mathrm{~mL}$. 
A solução irrigadora foi introduzida no interior do canal radicular por meio de cânula de $21 \mathrm{~mm}$ de comprimento e gauge 29 (Nav Tip, Ultradent Products Inc, South Jordan, USA).

Com a finalidade de remover possíveis raspas de dentina soltas no interior do canal radicular, os dentes tiveram seus canais radiculares lavados com $20 \mathrm{~mL}$ de água deionizada por meio de uma seringa com bico tipo Luer lock ${ }^{\circledR}$ (BD, São Paulo, Brasil) conectada a uma cânula plástica Capillary Tip (Ultradent Products Inc, South Jordan, USA). Posteriormente, os canais foram secos com cones de papel absorvente de numeração correspondente aos diâmetros cirúrgicos obtidos em cada amostra.

\section{Preparo das soluções utilizadas}

As soluções utilizadas foram aviadas no Laboratório de Pesquisa em Endodontia da FORP-USP. As soluções e amostras foram preparadas com reagentes de grau analítico e água purificada por meio de sistema de Osmose Reversa com Luz Ultravioleta (Quimis, Diadema, SP, Brasil) com condutividade elétrica inferior a $1 \mu \mathrm{S}$.

Ácido etilenodiaminotetraacético dissódico (EDTA 15\%).

Em um béquer para $200 \mathrm{~mL}$, pesaram-se 17 gramas de EDTA (Merck) e adicionou-se $100 \mathrm{~mL}$ de água deionizada. A solução formada, com coloração branca, foi agitada por meio de um agitador magnético e em seguida gotejou-se lentamente o hidróxido de sódio $5 \mathrm{~mol} . \mathrm{L}^{-1}$, até se obter $\mathrm{pH} 7,25$. Nesse momento, a solução que se encontrava com coloração branca, tornou-se límpida e transparente. $\mathrm{O} \mathrm{pH}$ da solução foi aferido por meio de um pHmetro Analion ${ }^{\circledR}$. O EDTA, depois de aviado, foi colocado em recipiente plástico âmbar, dotado de batoque e tampa.

Ácido acético $1 \%$

Em um balão volumétrico para $100 \mathrm{~mL}$, adicionou-se $1 \mathrm{~mL}$ de ácido acético (Sinthy, teor de ácido acético 99,7\%) completando-se o restante do volume com 
água deionizada. A solução formada de coloração cristalina foi homogeneizada e, na sequência, mediu-se o $\mathrm{pH}(2,60)$.

Ácido cítrico $10 \%$

Em um balão volumétrico para $100 \mathrm{~mL}$ foram adicionadas $10 \mathrm{~g}$ de ácido cítrico (Sigma) e completou-se o volume com água deionizada. A solução formada de coloração cristalina foi homogeneizada e o pH $(1,4)$ aferido por meio de um pHmetro Analion ${ }^{\circledR}$.

Quitosana 0,2\%

Em um béquer para $200 \mathrm{~mL}$, pesaram-se 0,2 gramas de quitosana (ACROS Organics) e adicionou-se $100 \mathrm{~mL}$ de ácido acético 1\%. A mistura, que inicialmente é heterogênea, foi agitada por meio de agitador magnético por 2 horas, aproximadamente. Ao final, obteve-se uma mistura homogênea cristalina com pH 3,2 .

\section{Distribuição dos grupos}

A amostra composta de 25 dentes foi distribuída aleatoriamente em 5 grupos experimentais com 5 dentes cada $(n=5)$, conforme a irrigação final adotada: $\mathrm{G} 1$ EDTA 15\%; G2 - solução de quitosana 0,2\%; G3 - ácido cítrico 10\%; G4 - ácido acético 1\%; G5 - controle (sem irrigação final).

Os espécimes receberam $5 \mathrm{~mL}$ da solução a ser analisada por um período de 3 minutos quantificados por um cronômetro. A solução foi introduzida no interior do canal radicular por meio de agulha 0,45 x 13 mm (BD, Franklin Lakes, NJ, USA - 26 G 1/2), a qual foi fixada na embocadura do canal, individualmente para cada espécime. A fixação da agulha ao dente foi realizada com resina fotopolimerizável Top Dan Blue ${ }^{\circledR}$ (FGM/Dentscare, Joinvile, CS, Brasil), recobrindo todo o acesso coronário para evitar possíveis refluxos da solução (Figura 1a).

Simultaneamente ao ato da irrigação, essas soluções eram coletadas em um tubo tipo falcon com capacidade para $15 \mathrm{~mL}$. Perfurou-se a tampa do tubo de modo a adaptar a porção radicular dos espécimes, de tal forma que os dentes foram 
colocados no furo com a coroa dental pra fora e a raiz para o lado de dentro da tampa. A fixação dos espécimes à tampa plástica foi realizada com Pritt Multi Tak® (Henkel Ltda, Itapevi, São Paulo, Brasil) (Figura 1b).

As soluções irrigantes, então, percorriam todo canal radicular no tempo estabelecido e saíam pelo forame apical caindo diretamente no tubo coletor (Figura 1c).

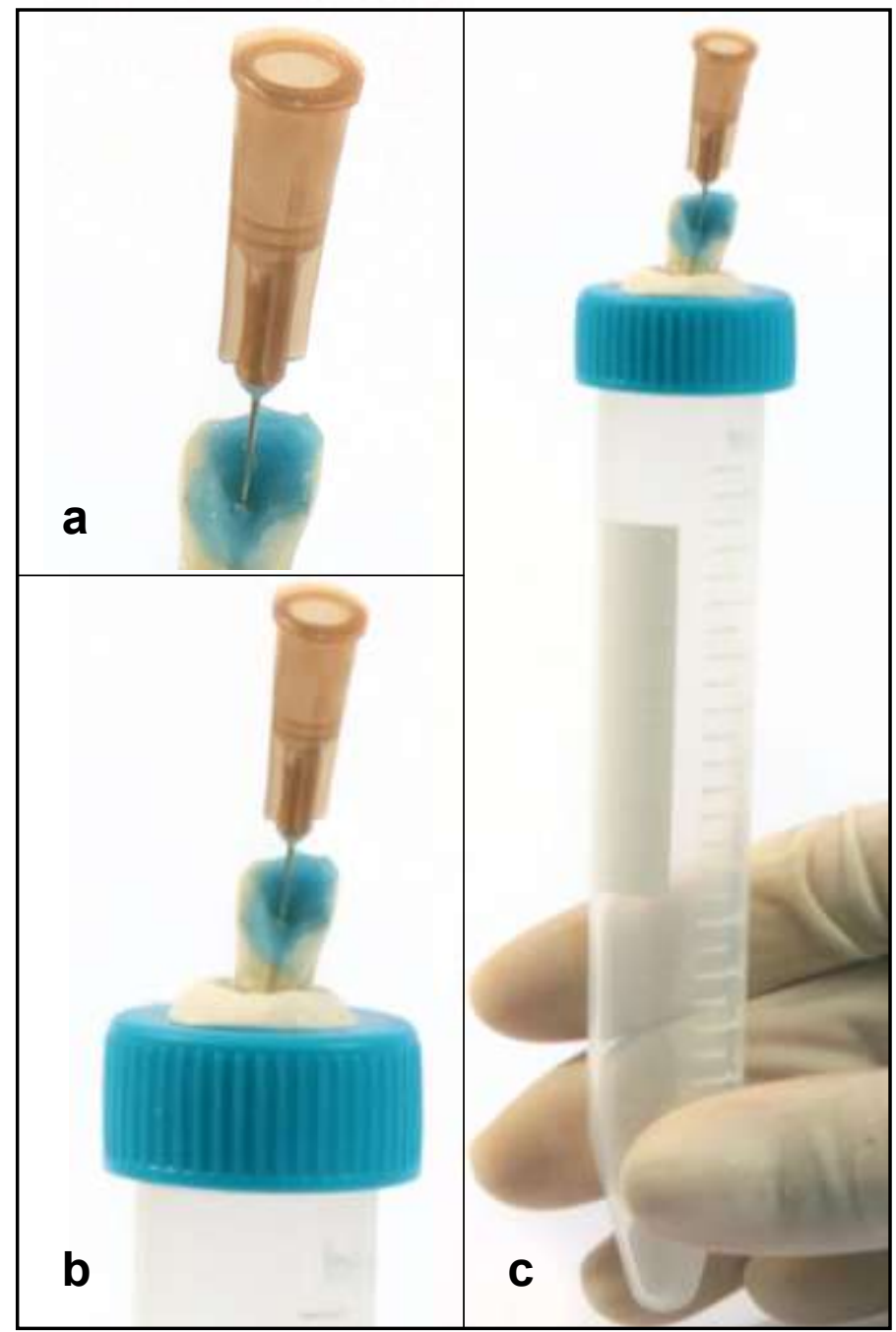

Figura 1 - a) Detalhe da agulha fixada na embocadura do canal; b) dente fixado na tampa do frasco coletor; c) Tubo coletor tipo Falcon

\section{Análise por Microscopia Eletrônica de Varredura}

Após a coleta de todas as amostras, a seringa de irrigação era desconectada da agulha adaptada à coroa dental, a tampa plástica utilizada para fixação do dente 
era desrosqueada do tubo falcon, o qual foi fechado com uma nova tampa, identificado e encaminhado para a espectrometria. Em ato contínuo, os espécimes foram irrigados com $10 \mathrm{~mL}$ de água deionizada, por meio de outra seringa conectada à agulha de irrigação, com finalidade de eliminar os resíduos das soluções avaliadas. Na sequência, os dentes receberam dois sulcos diametralmente opostos (faces vestibular e palatina) realizados com discos de carburundum acoplados à peça reta do micromotor (Dabi-Atlante, Ribeirão Preto, SP, Brasil). Nesta fase, tomou-se o cuidado em relação à profundidade do sulco realizado na estrutura dental, para que não houvesse exposição da câmara pulpar e ou do canal radicular, evitando assim, a deposição de resíduos dentinários sobre a superfície do canal a ser avaliada.

Por meio de cinzel bi-bizelado clivaram-se os espécimes longitudinalmente ao meio. A hemissecção com menos irregularidades e que melhor representou a extensão total do canal radicular foi selecionada para a análise por MEV.

Inicialmente, as hemissecções passaram por um processo de desidratação em uma bateria de álcool etílico ascendente $\left(40^{\circ}, 50^{\circ}, 70^{\circ}, 80^{\circ}\right.$ e $\left.96^{\circ} \mathrm{GL}\right)$, permanecendo por 1 hora em cada concentração alcoólica e, ao final, em álcool etílico absoluto por 24 horas. Em seguida os espécimes foram colocados em um dessecador até o momento da MEV, de forma a impedir a umidificação das amostras.

No momento da análise, os espécimes receberam uma cobertura ultrafina de material eletricamente condutor (aproximadamente 30 nanômetros), por meio de um processo denominado metalização. Na sequência, foram fixados com fita adesiva condutora de corrente elétrica em suportes metálicos onde receberam uma tênue camada de ouro, por meio do aparelho Desk II Denton Vacuum (Tóquio, Japão).

Para a realização da MEV utilizou-se um aparelho Jeol JSM5410 (Jeol, Tóquio, Japão) (Figura 2). Foram obtidas 50 fotomicrografias com aumento de 350X, referente aos terços médio e apical dos cinco espécimes de cada grupo, sendo 10 fotomicrografias por grupo e 5 para cada terço (médio e apical).

As fotomicrografias foram tabuladas sem identificação e submetidas a 3 examinadores, previamente calibrados, para avaliação da limpeza. Os avaliadores, doutores em Endodontia, atribuíram escores que variaram de 1 a 5 (Tabela 1) à cada fotomicrografia conforme a quantidade de smear layer presente nas paredes do canal radicular. 


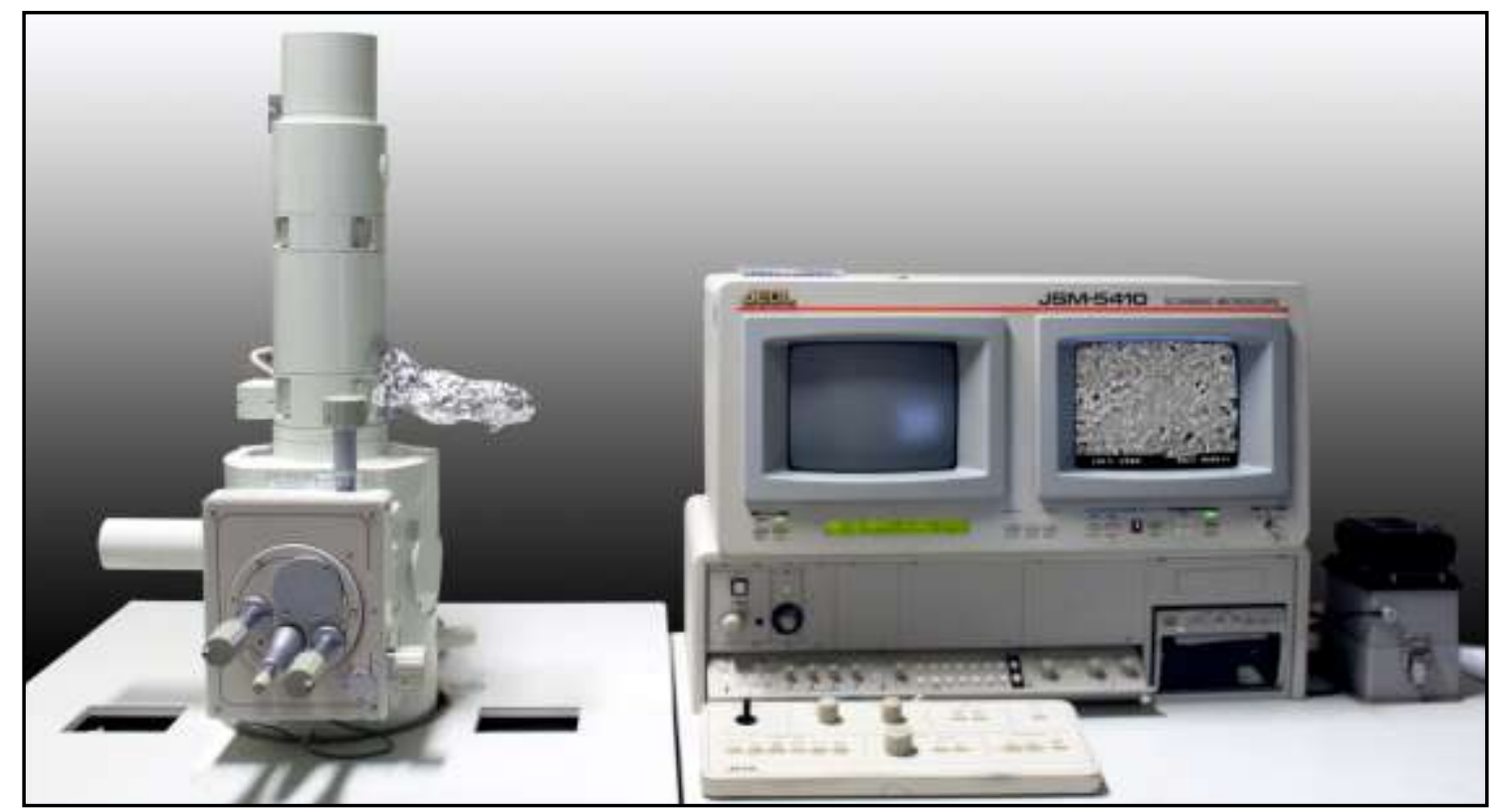

Figura 2 - Aparelho de microscopia eletrônica de varredura

Tabela 1. Escores utilizados para análise da limpeza.

\begin{tabular}{ll}
\hline Escores & Descrição \\
\hline 1 & Camada de smear recobrindo toda a superfície. \\
2 & Camada de smear recobrindo parcialmente a superfície e poucos túbulos visíveis. \\
3 & Cerca de metade da superfície com smear layer e metade com túbulos abertos. \\
4 & Camada de smear recobrindo pouca superfície e túbulos visíveis. \\
5 & Ausência da camada de smear na superfície. \\
\hline
\end{tabular}

Análise por Espectrometria de Absorção Atômica com Chama (F AAS).

Para a determinação da concentração de íons cálcio removidos pelas soluções desmineralizantes, utilizou-se um espectrômetro de absorção atômica com chama, modelo AAnalyst 800 (PerkinElmer, USA) (Figura 3), da Faculdade de Química de Ribeirão Preto - USP. Para medida dos sinais de absorbância, foram usadas lâmpadas de cátodo oco de cálcio PerkinElmer (Norwalk, EUA) e gás acetileno White Martins (SP, Brasil). O tempo de integração foi de 5 segundos. A vazão de acetileno, assim como, a altura do queimador foram ajustadas para se obter a melhor relação sinal/ruído. 


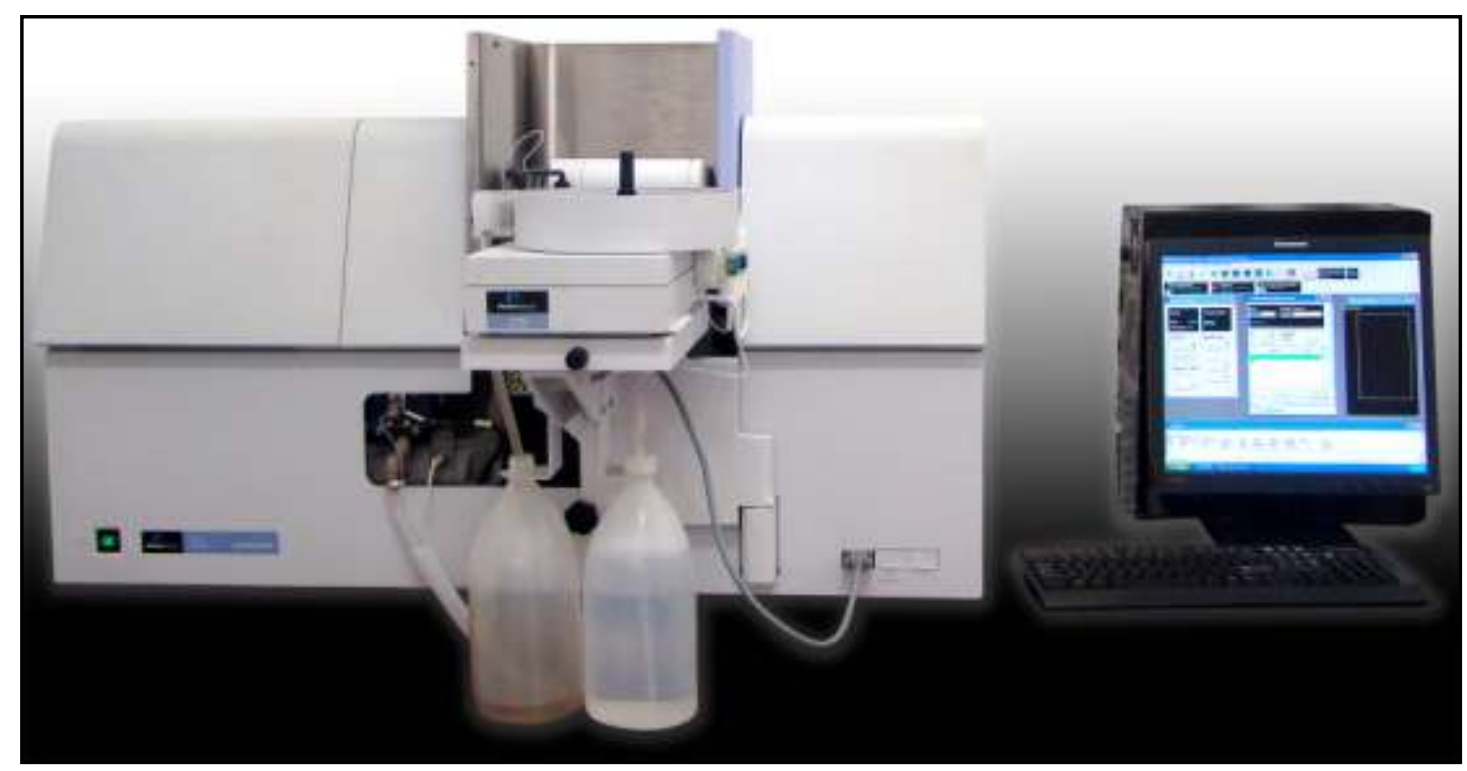

Figura 3 - Espectrômetro de absorção atômica com chama

Para o ajuste da curva de calibração para íons cálcio do espectrômetro utilizou-se uma solução padrão de cálcio de concentração $1000 \mathrm{mg} \cdot \mathrm{L}^{-1}$ (Ultra Scientific). As amostras das soluções de EDTA, ácido cítrico e ácido acético, antes de serem analisadas, foram diluídas em água deionizada para que as concentrações de cálcio se enquadrassem na curva de calibração, supracitada. Na amostra da solução de quitosana, especificamente, a diluição foi realizada em solução de lantânio 0,1\% (relação massa/volume), evitando assim, a interferência da matriz polimérica da quitosana na quantificação dos íons cálcio.

\section{Análise Estatística}

Os resultados obtidos referentes à análise da quantidade de íons cálcio revelados pela espectrometria de absorção atômica, assim como, os valores atribuídos à limpeza, por meio da MEV, foram tabulados, montando-se um arquivo de dados e posteriormente submetidos à análise estatística, por meio do software BioEstat 5.0. 


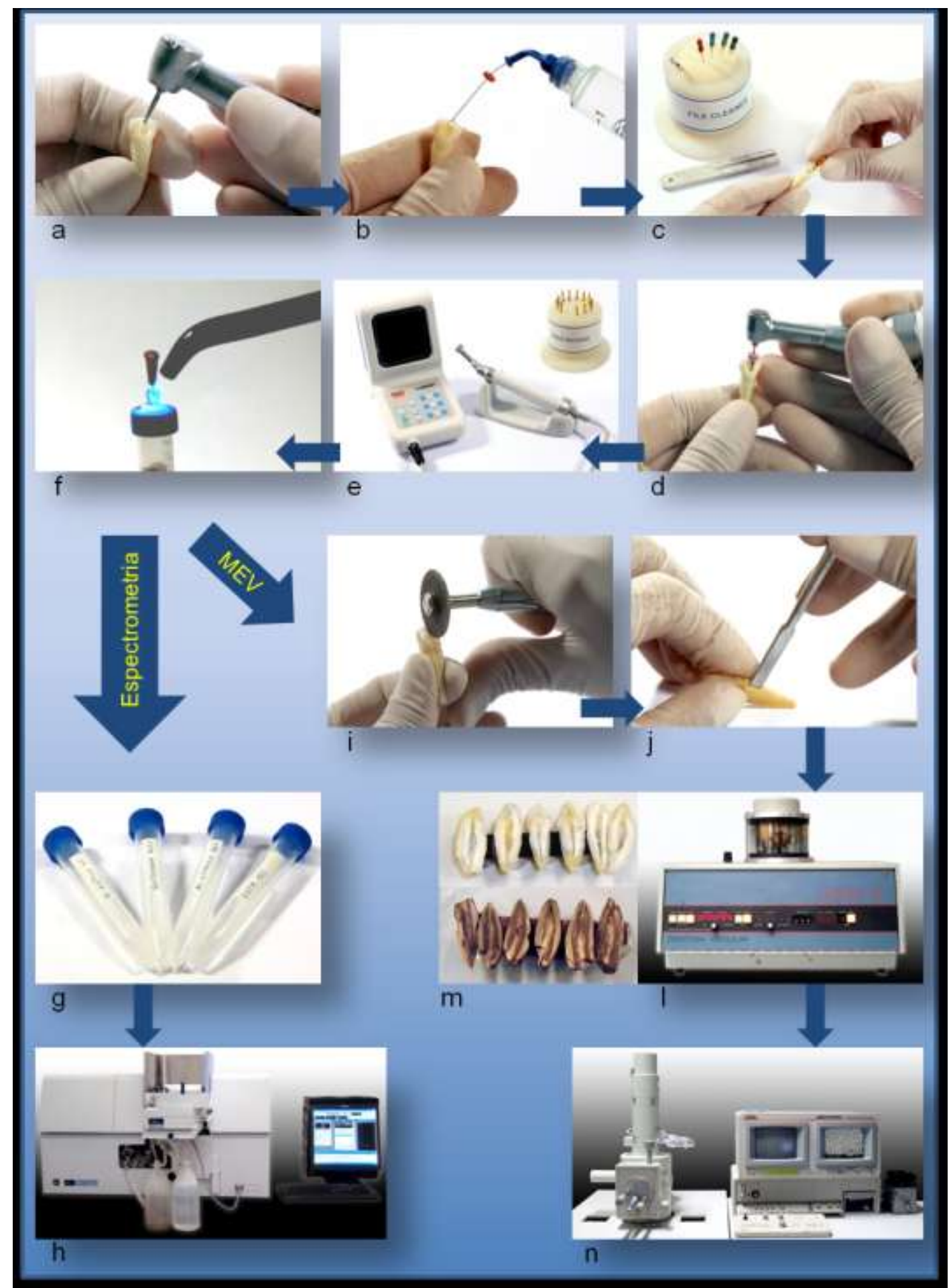

Figura 4 - Fluxograma da metodologia. a) cirurgia de acesso; b) Irrigação com solução de hipoclorito de sódio $1 \%$, após o acesso coronário e utilização de cada instrumento; c) determinação do diâmetro anatômico; d) instrumentação dos canais; e) Motor elétrico XSmart e instrumentos de níquel titânio Quantec®; f) preparo do dispositivo para irrigação final e coleta das substâncias quelantes; g) preparo das soluções coletadas para avaliação espectrometrica; h) Espectrometro; i) preparo dos espécimes para MEV; confecção dos sulcos diametralmente opostos na face vestibular e palatina; j) clivagem dos espécimes; I) aparelho Desk II Denton Vacuum (Tóquio, Japão); $\mathrm{m}$ ) espécimes antes e depois da metalização; n) aparelho Jeol JSM5410 (Jeol, Tóquio, Japão). 



\section{RESULTADOS}

Os resultados apresentados no presente estudo foram obtidos por meio da análise estatística dos dados provenientes de dois arquivos distintos, sendo um referente à quantidade de íons cálcio removidos pelas soluções avaliadas e outro, oriundo dos escores atribuídos à limpeza dos terços médio e apical do canal radicular. Dessa forma, visando facilitar a disposição e compreensão dos resultados, dividiu-se este capítulo em dois subitens, como segue abaixo:

Análise da limpeza dos terços médio e apical do canal radicular por meio da MEV

O conjunto matemático segue um modelo composto por um fator de variação, denominado soluções desmineralizantes, formado por 4 grupos experimentais: G1 (EDTA 15\%), G2 (quitosana 0,2\%), G3 (ácido cítrico 10\%), G4 (ácido acético 1\%) e um grupo controle (G5). 
Para cada grupo foram obtidas 10 fotomicrografias referentes às imagens representativas da limpeza do terço médio (5) e apical (5). Somaram-se, no total, 50 fotomicrografias as quais foram avaliadas por 3 examinadores que atribuíram escores que variaram de 1 a 5 conforme a quantidade de smear layer observada. Assim, obtiveram-se 150 dados de escores, 75 referentes ao terço médio e 75 ao terço apical. Montou-se uma tabela dos dados para o terço médio e outra para o apical. Os escores atribuídos ao terço médio pelos 3 examinadores podem ser vistos na Tabela 2.

Tabela 2 - Escores por grupo, referente a limpeza do terço médio do canal.

\begin{tabular}{cccccc}
\hline Amostras & $\begin{array}{c}\text { EDTA } \\
(\mathrm{G} 1)\end{array}$ & $\begin{array}{c}\text { quitosana } \\
(\mathrm{G} 2)\end{array}$ & $\begin{array}{c}\text { ác. cítrico } \\
(\mathrm{G} 3)\end{array}$ & $\begin{array}{c}\text { ác. acético } \\
(\mathrm{G} 4)\end{array}$ & $\begin{array}{c}\text { controle } \\
(\mathrm{G} 5)\end{array}$ \\
\hline 01 & 5 & 5 & 4 & 2 & 1 \\
02 & 5 & 4 & 4 & 3 & 1 \\
03 & 5 & 5 & 5 & 3 & 2 \\
04 & 5 & 5 & 4 & 3 & 1 \\
05 & 5 & 5 & 3 & 4 & 1 \\
& & & & & \\
01 & 5 & 5 & 4 & 2 & 1 \\
02 & 5 & 4 & 5 & 1 & 1 \\
03 & 3 & 4 & 4 & 1 & 1 \\
04 & 4 & 4 & 4 & 2 & 2 \\
05 & 5 & 4 & 5 & 3 & 1 \\
& & & & & \\
01 & 4 & 4 & 4 & 3 & 1 \\
02 & 5 & 5 & 5 & 3 & 1 \\
03 & 5 & 5 & 4 & 3 & 1 \\
05 & 5 & 4 & 4 & 2 & 1 \\
\hline
\end{tabular}

Por se tratar de escores a realização de teste estatístico paramétrico foi contra indicado, assim, realizou-se o teste não-paramétrico de Kruskal-Wallis, visto que os dados envolvidos são independentes (Tabela 3).

Tabela 3 - Teste de Kruskal-Wallis

\begin{tabular}{lc}
\hline Valor de $\mathrm{p}$ & $\mathrm{P}<0,0001$ \\
\hline As diferenças entre as médias são significantes? & $\mathrm{Sim}(\mathrm{p}<0,05)$ \\
\hline Número de grupos? & 05 \\
\hline $\mathrm{H}=$ & 58,8688 \\
\hline Graus de liberdade & 4 \\
\hline
\end{tabular}


Por meio do teste de Kruskal-Wallis foi possível observar diferença estatisticamente significante entre os grupos. Com finalidade de identificar quais entre os grupos eram diferentes entre si, realizou-se o teste de comparações múltiplas de Dunn, o qual está expresso na Tabela 4.

Tabela 4 - Teste de comparações múltiplas de Dunn

\begin{tabular}{lccc}
\hline Comparações múltiplas duas a duas & z calculado & z crítico & $\mathrm{p}$ \\
\hline G1 (EDTA15\%) X G2 (quitosana 0,2\%) & 0,7916 & 2,807 & $\mathrm{~ns}$ \\
G1 (EDTA15\%) X G3 (ác. cítrico 10\%) & 1,4744 & 2,807 & $\mathrm{~ns}$ \\
G1 (EDTA15\%) X G4 (ác. acético 1\%) & 4,4775 & 2,807 & $<0,05$ \\
G1 (EDTA15\%) X G5 (controle) & 6,1781 & 2,807 & $<0,05$ \\
G2 (quitosana 0,2\%) X G3 (ác. cítrico 10\%) & 0,6827 & 2,807 & $\mathrm{~ns}$ \\
G2 (quitosana 0,2\%) X G4 (ác. acético 1\%) & 3,6859 & 2,807 & $<0,05$ \\
G2 (quitosana 0,2\%) X G5 (controle) & 5,3865 & 2,807 & $<0,05$ \\
G3 (ác. cítrico 10\%) X G4 (ác. acético 1\%) & 3,0032 & 2,807 & $<0,05$ \\
G3 (ác. cítrico 10\%) X G5 (controle) & 4,7037 & 2,807 & $<0,05$ \\
G4 (ác. acético 1\%) X G5 (controle) & 1,7005 & 2,807 & ns \\
\hline
\end{tabular}

O teste de Dunn mostra claramente a formação de 2 grupos de soluções. Um formado pelo EDTA $15 \%$, quitosana $0,2 \%$ e ácido cítrico $10 \%$ e outro pelo ácido acético $1 \%$ e grupo controle. No primeiro, as soluções envolvidas promoveram a limpeza das paredes do terço médio do canal radicular de forma semelhante entre si e diferente estatisticamente $(p<0,05)$ do segundo grupo. O ácido acético $1 \%$ não foi capaz de remover a smear layer, apresentando resultado estatisticamente semelhante ao grupo controle.

A Figura 5 destaca a diferença entre as médias encontradas na comparação entre os grupos. Observam-se os maiores valores, com diferença entre as médias superiores a 40, entre os grupos G1-G5 e G2-G5 $(p<0,05)$. A relação entre os grupos G1-G4 e G3-G5 apresentaram valores diferenciais entre as médias acima de 30. Esses resultados revelaram a alta capacidade das soluções de EDTA 15\%, quitosana $0,2 \%$ e ácido cítrico $10 \%$ em remover a smear layer do terço médio do canal radicular quando comparadas isoladamente ao grupo do ácido acético $1 \%$ e controle.

Para análise da capacidade de limpeza das soluções no terço apical do canal radicular utilizou-se os dados da Tabela 5 , referente aos escores atribuídos para cada solução. 


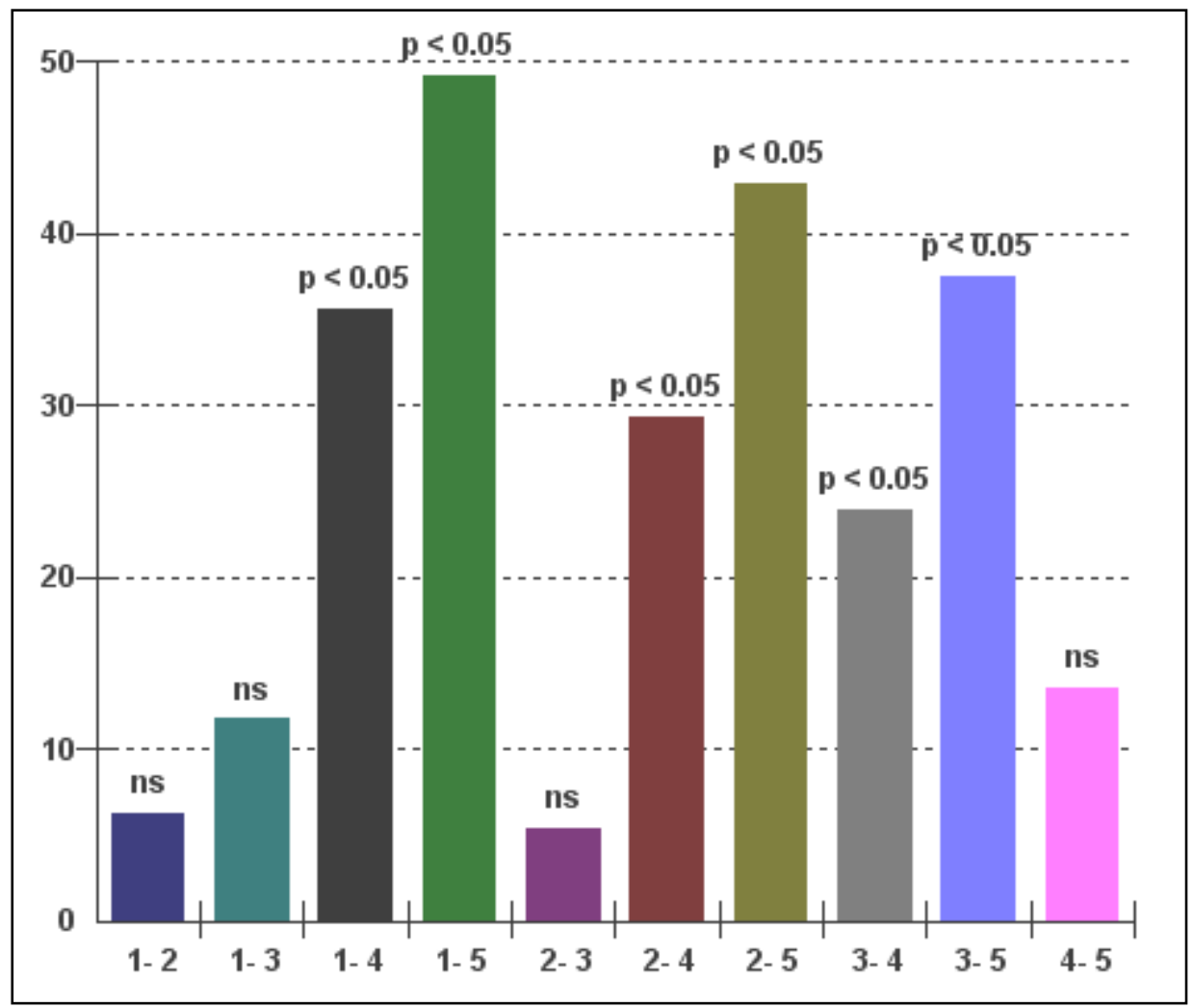

Figura 5- Representação gráfica da diferença entre as médias com o grau de significância entre as soluções no terço médio (G1-EDTA 15\%; G2- quitosana 0,2\%; G3- ác. cítrico 10\%; G4- ác. acético 1\%; G5-controle).

Tabela 5 - Escores por grupo, referente a limpeza do terço apical do canal.

\begin{tabular}{|c|c|c|c|c|c|}
\hline Amostras & $\begin{array}{c}\text { EDTA } \\
\text { (G1) }\end{array}$ & $\begin{array}{l}\text { quitosana } \\
\text { (G2) }\end{array}$ & $\begin{array}{l}\text { ác. cítrico } \\
\text { (G3) }\end{array}$ & $\begin{array}{l}\text { ác. acético } \\
\text { (G4) }\end{array}$ & $\begin{array}{c}\text { controle } \\
\text { (G5) }\end{array}$ \\
\hline 01 & 1 & 5 & 3 & 1 & 1 \\
\hline 02 & 1 & 5 & 3 & 2 & 1 \\
\hline 03 & 1 & 5 & 5 & 1 & 1 \\
\hline 04 & 5 & 5 & 5 & 1 & 1 \\
\hline 05 & 5 & 5 & 5 & 2 & 1 \\
\hline 01 & 4 & 5 & 1 & 1 & 1 \\
\hline 02 & 5 & 4 & 3 & 1 & 1 \\
\hline 03 & 5 & 4 & 2 & 1 & 1 \\
\hline 04 & 5 & 4 & 1 & 2 & 1 \\
\hline 05 & 5 & 4 & 5 & 1 & 1 \\
\hline 01 & 5 & 3 & 5 & 2 & 1 \\
\hline 02 & 5 & 3 & 4 & 3 & 1 \\
\hline 03 & 5 & 4 & 3 & 1 & 1 \\
\hline 04 & 5 & 3 & 3 & 1 & 1 \\
\hline 05 & 5 & 3 & 3 & 1 & 1 \\
\hline
\end{tabular}


A Tabela 6 mostra o teste não-paramétrico de Kruskal-Wallis evidenciando que as soluções avaliadas agiram de forma estatisticamente diferente na limpeza do terço apical.

No sentido de identificar quais os agentes desmineralizantes eram diferentes entre si, realizou-se o teste de comparações múltiplas de Dunn (Tabela 7).

Tabela 6 - Teste de Kruskal-Wallis

\begin{tabular}{lc}
\hline Valor de $\mathrm{p}$ & $\mathrm{P}<0,0001$ \\
\hline As diferenças entre as médias são significantes? & $\operatorname{Sim}(\mathrm{p}<0,05)$ \\
\hline Número de grupos? & 05 \\
\hline $\mathrm{H}=$ & 45,5397 \\
\hline Graus de liberdade & 4 \\
\hline
\end{tabular}

Tabela 7 - Teste de comparações múltiplas de Dunn

\begin{tabular}{lccc}
\hline Comparações múltiplas duas a duas & z calculado & z crítico & $\mathrm{p}$ \\
\hline G1 (EDTA15\%) X G2 (quitosana 0,2\%) & 0,0419 & 2,807 & $\mathrm{~ns}$ \\
G1 (EDTA15\%) X G3 (ác. cítrico 10\%) & 1,0346 & 2,807 & $\mathrm{~ns}$ \\
G1 (EDTA15\%) X G4 (ác. acético 1\%) & 4,0042 & 2,807 & $<0,05$ \\
G1 (EDTA15\%) X G5 (controle) & 4,8043 & 2,807 & $<0,05$ \\
G2 (quitosana 0,2\%) X G3 (ác. cítrico 10\%) & 0,9927 & 2,807 & $\mathrm{~ns}$ \\
G2 (quitosana 0,2\%) X G4 (ác. acético 1\%) & 3,9624 & 2,807 & $<0,05$ \\
G2 (quitosana 0,2\%) X G5 (controle) & 4,7624 & 2,807 & $<0,05$ \\
G3 (ác. cítrico 10\%) X G4 (ác. acético 1\%) & 2,9697 & 2,807 & $<0,05$ \\
G3 (ác. cítrico 10\%) X G5 (controle) & 3,7697 & 2,807 & $<0,05$ \\
G4 (ác. acético 1\%) X G5 (controle) & 0,8000 & 2,807 & ns \\
\hline
\end{tabular}

Semelhante aos resultados referentes ao terço médio, o teste de Dunn mostrou que no terço apical as soluções de EDTA 15\%, quitosana 0,2\% e ácido cítrico $10 \%$ também limparam as paredes do canal radicular de forma semelhante entre si e diferente estatisticamente $(p<0,05)$ do ácido acético $1 \%$. Este último mostrou-se semelhante estatisticamente ao grupo controle evidenciando a ausência de capacidade de limpeza da solução.

Por meio da Figura 6 observa-se a diferença entre as médias encontradas na comparação entre os grupos no terço apical. Verificaram-se os maiores valores, com diferença entre as médias maiores que 30 , entre os grupos G1-G4, G1-G5, G2-G4, G2-G5 e G3-G5 ( $p<0,05)$, e superior a 20 entre G3-G4 $(p<0,05)$, evidenciando a maior capacidade das soluções de EDTA 15\%, quitosana 0,2\% e ácido cítrico $10 \%$ 
em remover a smear layer do terço apical em relação ao ácido acético $1 \%$ e grupo controle.

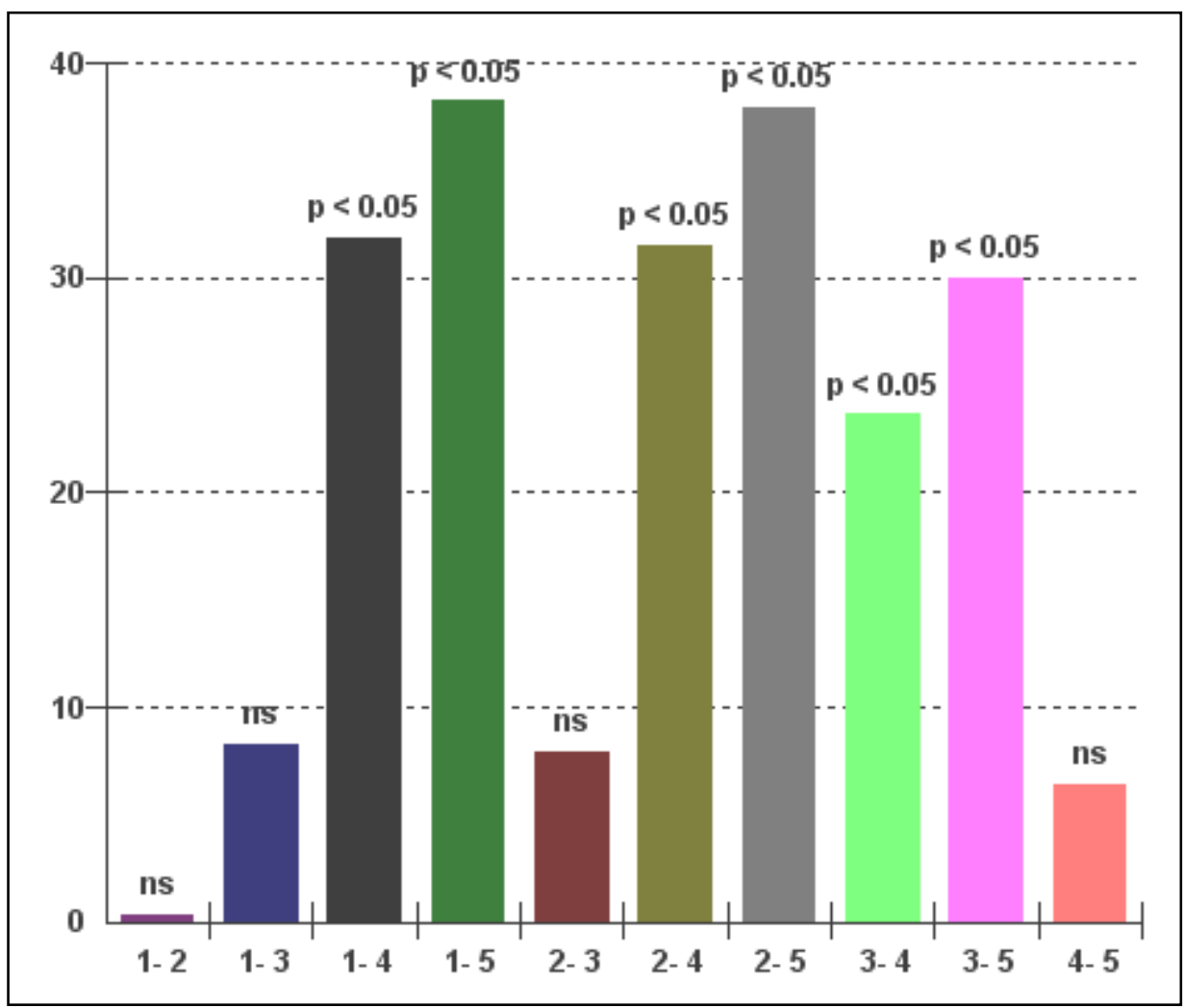

Figura 6- Representação gráfica da diferença entre as médias com o grau de significância entre as soluções no terço apical (G1-EDTA 15\%; G2- quitosana 0,2\%; G3- ác. cítrico 10\%; G4- ác. acético 1\%; G5-controle).

Na sequência, realizou-se o teste de Kruskal-Wallis entre os terços médio e apical para as soluções de EDTA $15 \%$, quitosana $0,2 \%$ e ácido cítrico $10 \%$, individualmente, com objetivo de verificar se a capacidade de limpeza foi igual ou maior em um terço do que no outro. Os valores do teste para o grupo do EDTA 15\% $(p=0,51)$, quitosana $0,2 \%(p=0,28)$ e ácido cítrico $10 \%(p=0,09)$ mostraram que as soluções promoveram a limpeza dos terços médio e apical de forma semelhante, não havendo diferença estatisticamente significante. As Figuras de 7 a 9 ilustram a representação gráfica da diferença entre as médias dos postos entre os terços médio e apical para cada solução. 
As Figuras 10 e 11 mostram fotomicrografias dos terços médio e apical dos espécimes após irrigação final com as soluções desmineralizantes.

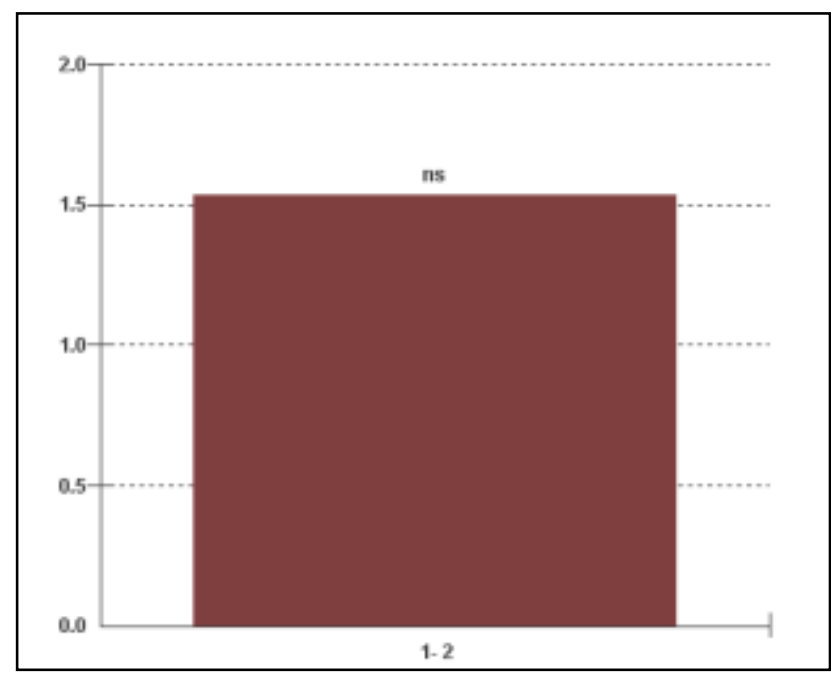

Figura 7- Representação gráfica da diferença entre as médias dos postos dos terços médio e apical para o grupo do EDTA $15 \%$.

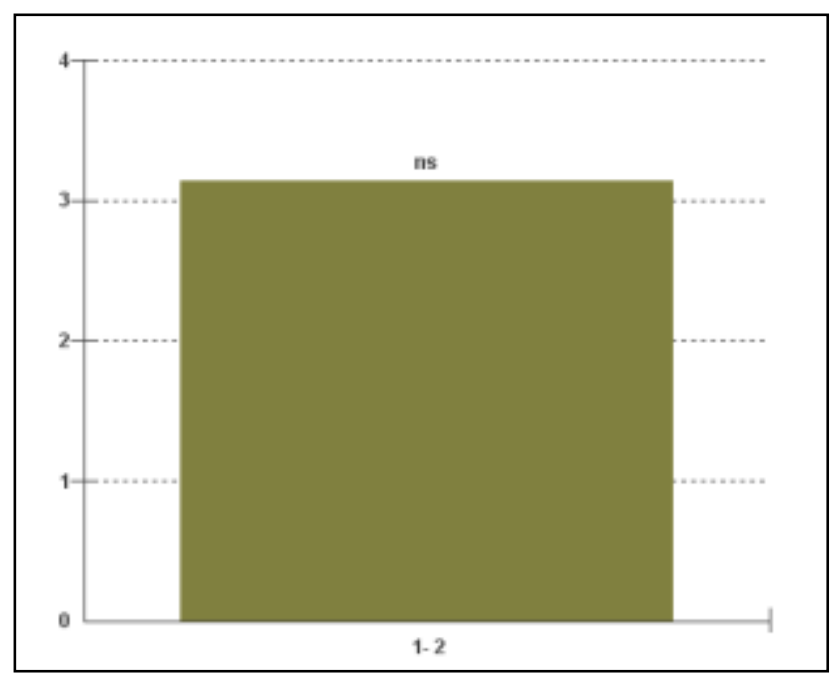

Figura 8- Representação gráfica da diferença entre as médias dos postos dos terços médio e apical para o grupo da quitosana $0,2 \%$. 


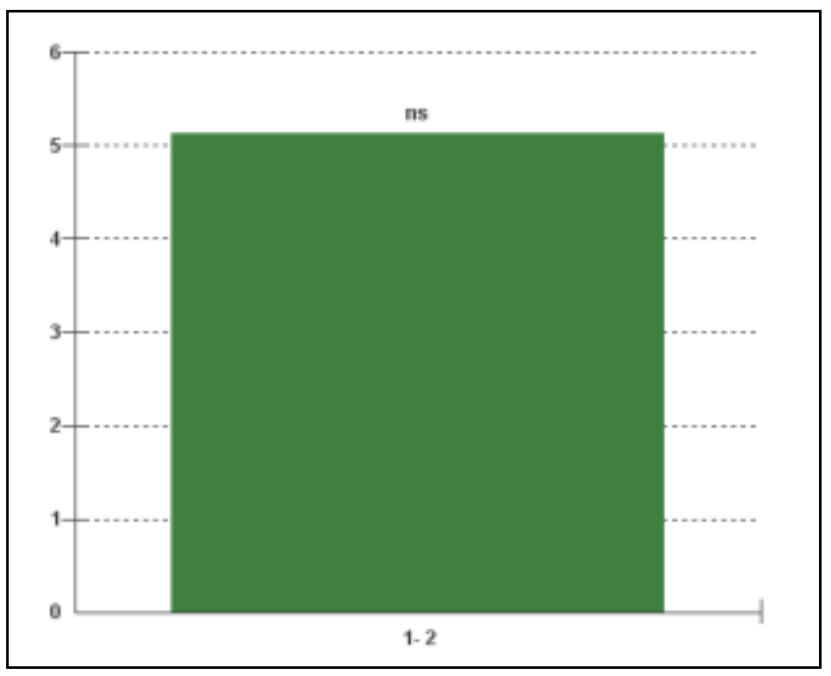

Figura 9- Representação gráfica da diferença entre as médias dos postos dos terços médio e apical para o grupo do ácido cítrico $10 \%$. 


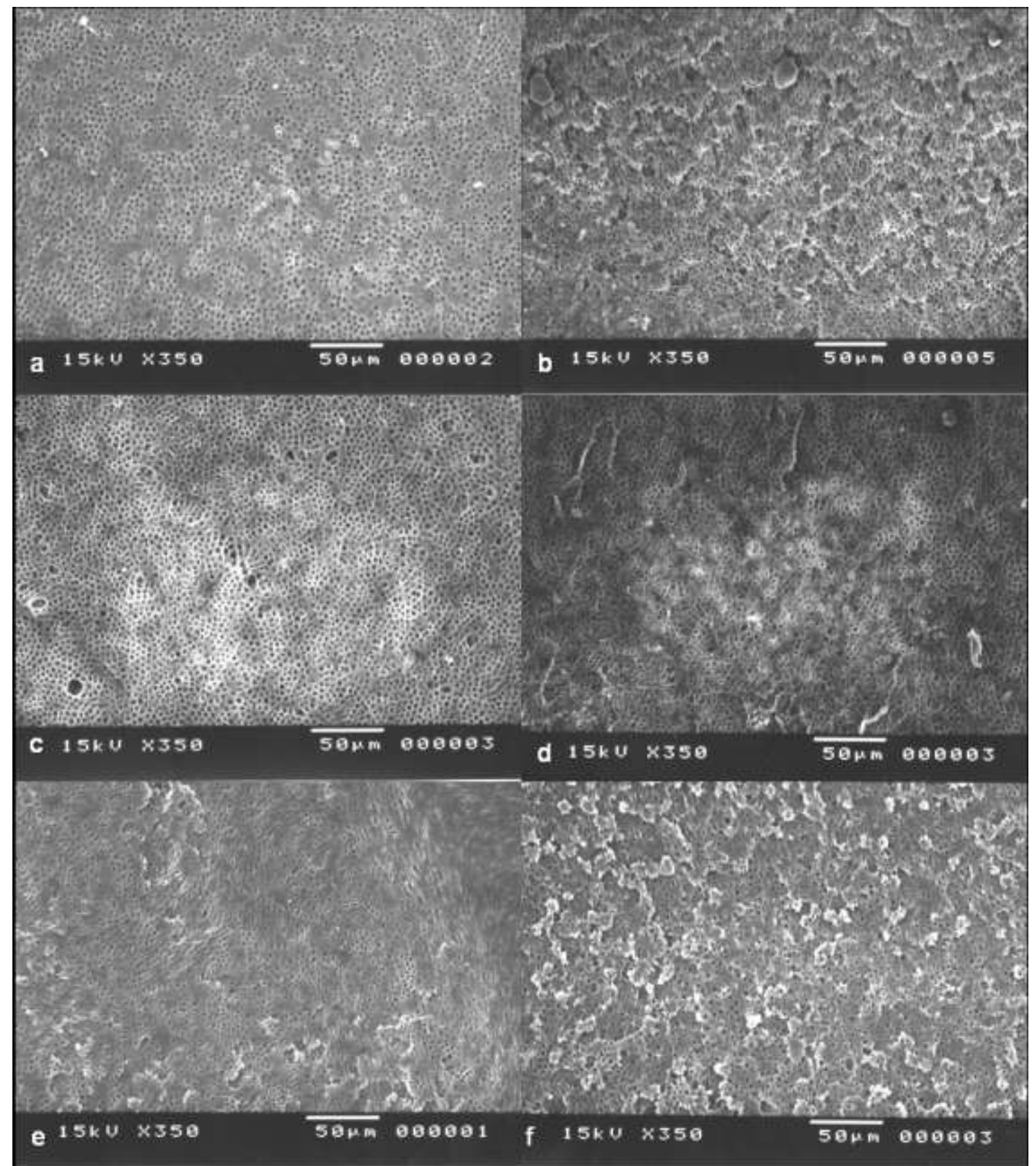

Figura 10 - Fotomicrografias da dentina dos terços médio e apical (350X). (a) terço médio do grupo do EDTA 15\% evidenciando total desobstrução dos túbulos dentinários; (b) região apical do grupo do EDTA 15\%; (c) terço médio da dentina irrigada com quitosana $0,2 \%$ mostrando ausência da smear layer; (d) terço apical tratado com quitosana 0,2\% evidenciando grande quantidade de túbulos dentinários desobstruídos; (e) paredes do terço médio irrigadas com ácido cítrico 10\%. Observa-se remoção da smear layer com túbulos desobstruídos; (f) região apical do grupo do ácido cítrico $10 \%$ com grande quantidade de túbulos dentinários desobstruídos. 


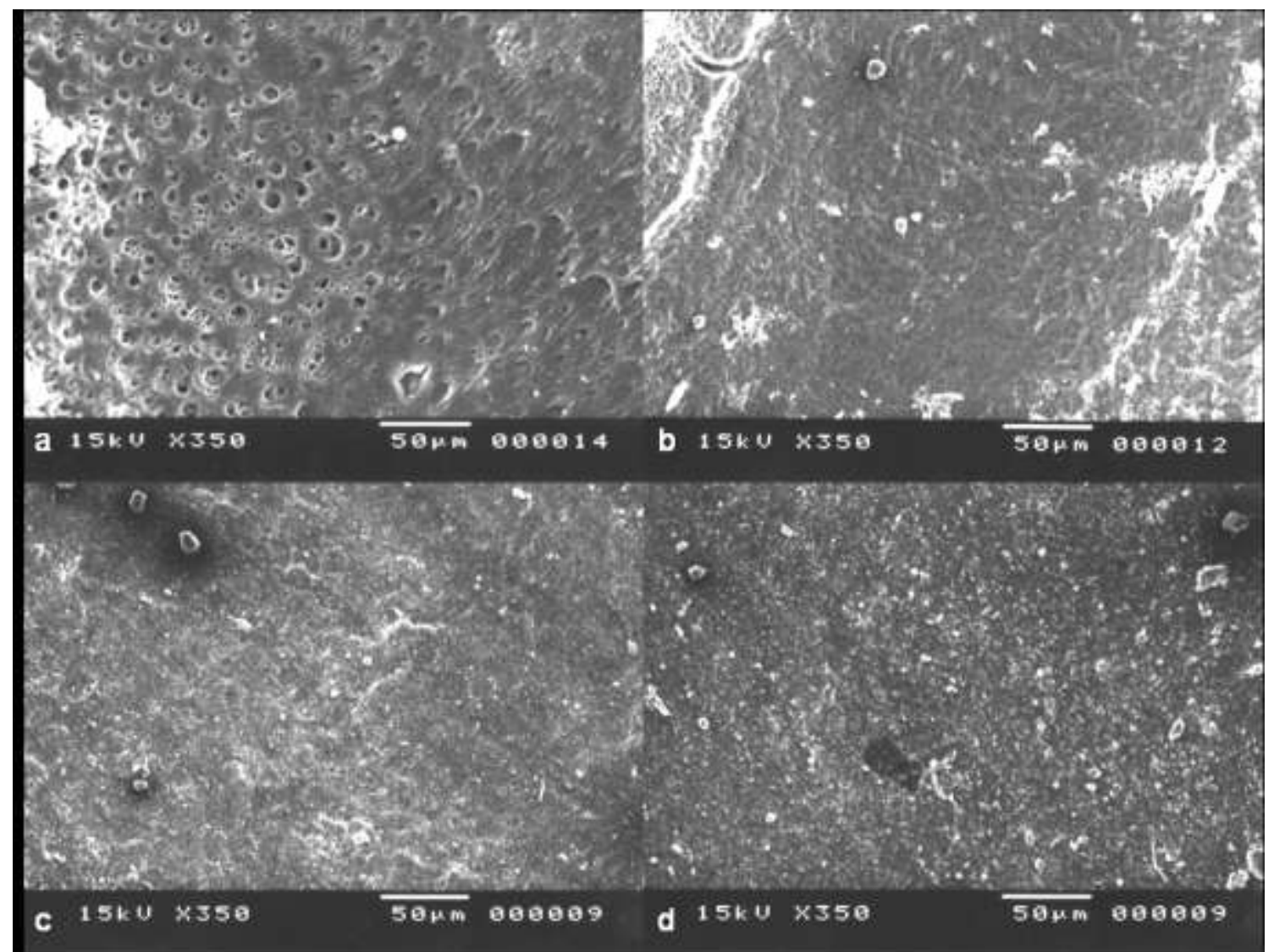

Figura 11 - Fotomicrografias com aumento de 350X. a e b) terços médio e apical, respectivamente, do grupo do ácido ácético $1 \%$ evidenciando grande quantidade de smear layer nas paredes dentinárias; terços médio (c) e apical (d) do grupo controle com presença de smear layer por toda região.

\section{Análise da concentração de íons cálcio removidos pelas soluções.}

O modelo matemático do experimento apresenta um único fator de variação, denominado irrigação final, com 4 componentes: G1 no qual realizou-se a irrigação final com EDTA 15\%; G2 que recebeu irrigação final com solução de quitosana 0,2\%; G3 no qual utilizou-se o ácido cítrico 10\% na irrigação final e; G4 cuja irrigação final foi com ácido acético $1 \%$.

Foram obtidos 20 dados provenientes da mensuração da concentração de cálcio, dada em miligramas por litro, após a irrigação final de 5 espécimes por grupo do agente desmineralizante $(5 \times 4=20)$.

A Tabela 8 mostra os valores obtidos da concentração de cálcio por solução, as médias e o desvio padrão. 
Tabela 8 - Valores da concentração de cálcio por solução

\begin{tabular}{ccccc}
\hline Amostra & EDTA & Quitosana & Ác. cítrico & Ác. acético \\
\hline 1 & 115,1 & 89,31 & 70,36 & 17,61 \\
2 & 123,6 & 101,6 & 85,21 & 26,21 \\
3 & 123,8 & 100,6 & 76,50 & 25,05 \\
4 & 118,3 & 137,19 & 56,63 & 21,28 \\
5 & 128,2 & 91,95 & 63,23 & 37,96 \\
\hline Médias $\pm D P$ & $121,80 \pm 5,13$ & $104,13 \pm 19,23$ & $70,38 \pm 11,15$ & $25,62 \pm 7,68$ \\
\hline
\end{tabular}

Os valores da Tabela 8 foram submetidos à análise estatística, por meio do software BioEstat 5.0, com nível de significância de $5 \%(\alpha=0,05)$. O programa evidenciou que a amostra testada apresentou distribuição normal. Tal informação aliada ao modelo matemático do experimento faculta a realização do teste paramétrico de Análise de Variância (one-Way ANOVA) seguido pelo teste complementar de Tukey-Kramer. A Tabela 9 apresenta os resultados da Análise de Variância.

Tabela 9 - Resultados da Análise de Variância

\begin{tabular}{c|c|c|c|c|c}
\hline $\begin{array}{c}\text { Fontes de } \\
\text { variação }\end{array}$ & $\begin{array}{c}\text { Soma dos } \\
\text { quadrados }\end{array}$ & $\begin{array}{c}\text { Grau de } \\
\text { liberdade }\end{array}$ & $\begin{array}{c}\text { Quadrado } \\
\text { médio }\end{array}$ & Valor de F & Valor de $p$ \\
\hline Tratamentos & 26890 & 3 & 8963,3 & 61,8512 & $<0,0001$ \\
Resíduos & 2318,7 & 16 & 144,92 & & \\
\hline Total & 29208 & 19 & & & \\
\hline
\end{tabular}

A Análise de Variância evidenciou que a diferença entre as medianas é bastante significante, uma vez que o valor de $p$ calculado é muito inferior a 0,05 $(p<0,0001)$. Com a finalidade de esclarecer quais dentre as soluções apresentavam diferenças entre si, realizou-se o teste complementar de Tukey-Kramer, o qual pode ser visto na Tabela 10.

Tabela 10 - Teste de Tukey entre soluções

\begin{tabular}{ccc}
\hline Soluções & Médias & Valor crítico ó $=0,05$ \\
\hline EDTA & $121,8 \mathbf{\Delta}$ & \\
Quitosana & $104,1 \mathbf{\Delta}$ & 4,046 \\
Ac. cítrico & $70,38 \bullet$ & \\
Ac. acético & $25,62 \mathbf{\Delta}$ & \\
\hline
\end{tabular}

Símbolos diferentes representam valores estatisticamente diferentes 
A análise do teste complementar de Tukey-Kramer possibilitou a composição das soluções quelantes e desmineralizantes avaliadas em três grupos distintos. Um grupo formado pelo EDTA $15 \%$ e quitosana $0,2 \%$, outro pelo ácido cítrico $10 \%$ e um terceiro formado pelo ácido acético $1 \%$.

As soluções de EDTA $15 \%$ e quitosana $0,2 \%$ removeram as maiores concentrações de íons cálcio do canal radicular, de forma semelhante entre si e diferente estatisticamente dos demais grupos $(p<0,01)$.

As menores concentrações de íons cálcio foram observadas no grupo do ácido acético $1 \%$. O ácido cítrico $10 \%$ apresentou valores da concentração de cálcio intermediários ao grupo formado pelo EDTA $15 \%$ e quitosana $0,2 \%$ e ao grupo do ácido acético 1\%, sendo diferente estatisticamente de ambos $(p<0,01)$.

A Figura 12 ilustra o gráfico da diferença entre as médias entre os grupos estudados e o grau de significância entre eles.

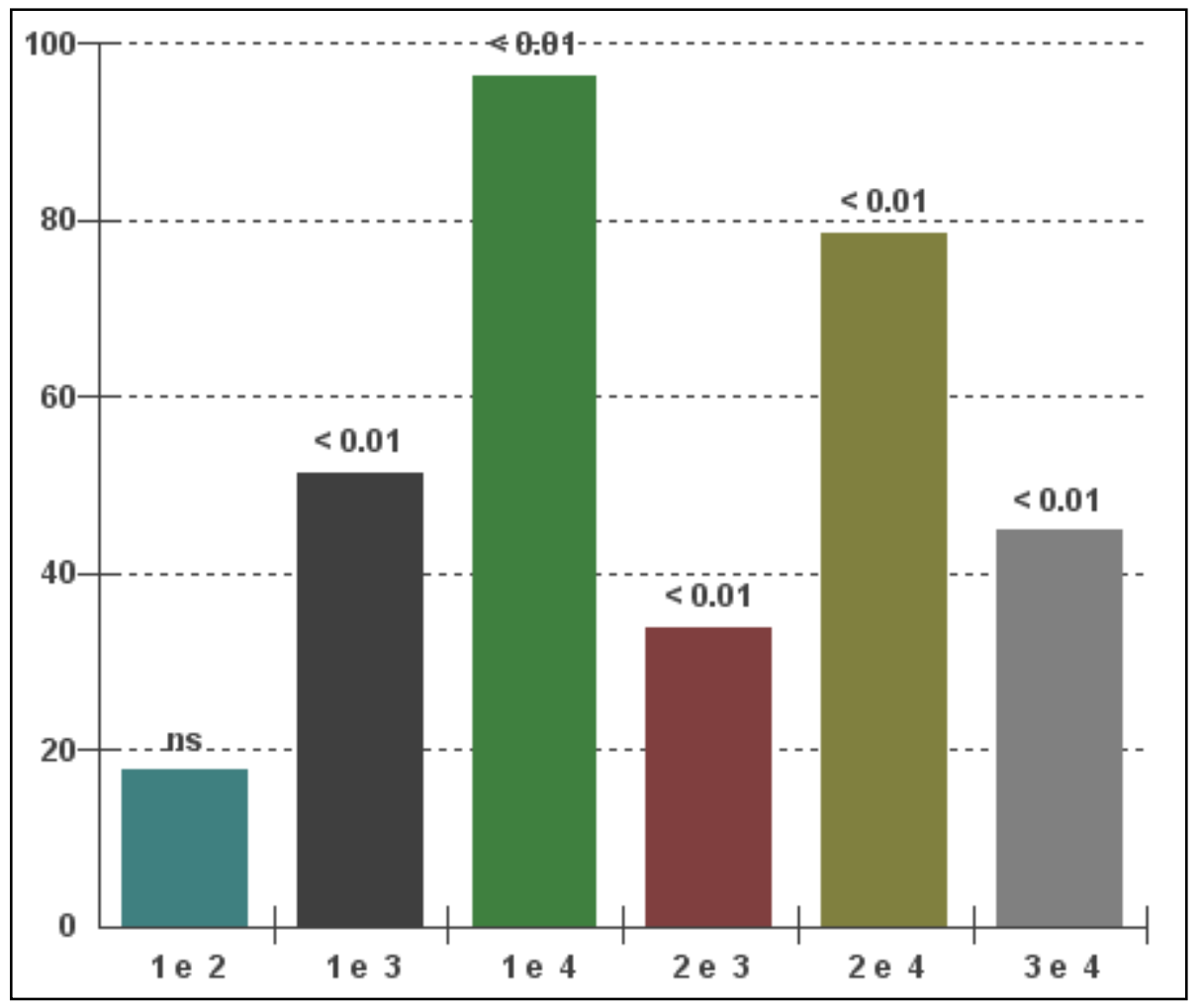

Figura 12 - Representação gráfica da diferença entre as médias com o grau de significância entre os grupos (G1-EDTA; G2- quitosana; G3- ác. cítrico e G4- ác. acético). 


\section{DISCUSSÃO}

O presente estudo comparou a capacidade de remoção da smear layer do canal radicular entre diferentes soluções quelantes e desmineralizantes. A eficiência das soluções testadas em remover essa camada foi avaliada de duas formas. $\mathrm{Na}$ primeira, a microscopia eletrônica de varredura possibilitou analisar a limpeza das paredes dentinárias dos terços médio e apical com aumento de 350x após ação das soluções. Na segunda, a espectrometria de absorção atômica com chama permitiu quantificar a concentração de íons cálcio em $\mathrm{mg} \mathrm{L}^{-1}$ presentes nas soluções coletadas após irrigação. Por meio dessa última análise foi possivel verificar, dentre as soluções, qual apresentava maior capacidade desmineralizante sobre a porção inorgânica da smear layer e nas paredes dentinárias.

Os resultados da MEV mostraram que os grupos do EDTA 15\%, quitosana 0,2\% e ácido cítrico $10 \%$ promoveram a limpeza das paredes dos canais radiculares de forma semelhante entre si e estatisticamente diferente do ácido acético $1 \% \mathrm{e}$ controle $(p<0,05)$. 
A eficiência do EDTA em remover a smear layer já é bastante conhecida e documentada na literatura (MARQUES et al., 2006; KHEDMAT; SHOKOUHINEJAD, 2008; MANCINI et al., 2009; SPANÓ et al., 2009; PRADO et al., 2011). A associação do EDTA ao hipoclorito de sódio tem sido amplamente utilizada para a promoção de paredes dentinárias isentas de smear layer e túbulos dentinários desobstruídos (ŞEN; ERTURK; PIŞKIN, 2009; SILVA et al., 2008; MELLO et al. 2010). No entanto, há relatos de que essa associação tem proporcionado extensa erosão do tecido dentinário (MAl et al. 2010; ZHANG et al. 2010).

O ácido cítrico é um ácido orgânico fraco com capacidade de reagir rapidamente com íons cálcio, além de apresentar citotoxicidade relativamente baixa (PAPAGIANNI, 2007). No presente estudo, o ácido cítrico 10\% mostrou-se semelhante ao EDTA $15 \%$ quando comparada a capacidade de ambos em remover a smear layer. Resultados similares foram obtidos por Spanó et al. (2009). Os autores avaliaram, comparativamente, a capacidade de limpeza das soluções de EDTA $15 \%$, ácido cítrico 10\%, citrato de sódio 10\%, vinagre de maçã, ácido acético $5 \%$, ácido málico $5 \%$ e hipoclorito de sódio $1 \%$. A MEV evidenciou que o EDTA e o ácido cítrico removeram totalmente a camada de smear de forma estatisticamente semelhante entre si. Estudos anteriores nos quais utilizaram o ácido cítrico na mesma concentração e para a mesma finalidade, corroboram os achados do presente trabalho (HAZNEDAROĞLU, 2003; SCELZA et al., 2004; KHEDMAT; SHOKOUHINEJAD, 2008; PRADO et al., 2011).

A solução de quitosana $0,2 \%$, como evidenciado anteriormente, apresentou resultados estatisticamente semelhantes ao EDTA 15\% e ácido cítrico 10\%, no que se refere à limpeza. À primeira impressão chama a atenção para o fato de que a solução, mesmo em baixa concentração, foi capaz de remover a smear layer da mesma maneira que soluções bem mais concentradas. É relevante salientar que os escores atribuídos pelos examinadores ao grupo da quitosana $0,2 \%$ foram significantemente maiores aos do ácido acético 1\% $(p<0,05)$, ou ainda, a limpeza das paredes dentinárias promovida pela quitosana $0,2 \%$ foi superior às tratadas com ácido acético 1\%. Tal informação torna-se importante, uma vez que a solução de quitosana utilizada neste experimento foi obtida por meio da diluição em ácido acético $1 \%$. Dessa forma, pela análise dos resultados fica evidente que capacidade de remoção da smear layer deve-se às propriedades da quitosana e não à do ácido 
acético $1 \%$, visto que este último mostrou-se estatisticamente semelhante ao grupo controle.

A propriedade quelante da quitosana evidenciada, pioneiramente, neste estudo indica que esta solução agiu satisfatoriamente sobre a porção inorgânica da smear layer favorecendo a remoção desta camada. Embora não tenha sido, até então, documentado na literatura o efeito quelante da quitosana na endodontia, essa propriedade tem sido vastamente explorada pela indústria na recuperação de íons metálicos no tratamento de águas residuais e na purificação de água potável para redução de metais indesejados (ONSØYEN; SKAUGRUD, 1990).

Processos de adsorção, troca iônica e quelação são os prováveis mecanismos responsáveis pela formação de complexos entre quitosana e íons metálicos. O tipo de interação que ocorre depende do íon envolvido, da estrutura química da quitosana e do pH da solução (GUIBAL; MILOT; ROUSSY, 2000; RHAZI et al., 2002). Dois modelos são relatados na literatura como possíveis mecanismos de ação. Um deles, conhecido como modelo da ponte, baseia-se na teoria de que dois ou mais grupos aminos de uma cadeia de quitosana ligam-se a um mesmo íon metálico (BLAIR; HO, 1981; FOCHER et al.,1986). O outro defende a teoria de que apenas um grupo amino da estrutura da substância é envolvido na ligação, estando o íon "ancorado" ao grupo amino (DOMARD, 1987; PIRON e DOMARD, 1998).

Em relação à limpeza entre os terços médio e apical, a análise estatística mostrou não haver diferença significante para cada solução, ou seja, a remoção da smear layer ocorreu indistintamente nos dois terços. Mancini et al. (2009) verificaram que as soluções de EDTA $17 \%$ e Bio-pure MTAD removeram a smear layer do terço médio do canal, mas não foram capazes de limpar o terço apical. A divergência nos resultados pode ser explicada, uma vez que no presente estudo para que as amostras pudessem ser coletadas e submetidas à espectrometria, os ápices dos espécimes foram desobstruídos. Assim, durante o ato da irrigação, a solução percorreu todo canal radicular desembocando diretamente no tubo coletor através do forame apical. Dessa forma, no mesmo período de tempo, o volume do agente quelante que agiu no terço médio foi o mesmo do terço apical.

A análise por meio da espectrometria de absorção atômica com chama mostrou que as quatro soluções avaliadas removeram íons cálcio do canal radicular. A presença de cálcio na solução após a irrigação não é proveniente, 
exclusivamente, da descalcificação da estrutura inorgânica da smear layer. As soluções quelantes e desmineralizantes atuam sobre o cálcio da matriz de hidroxiapatita da dentina, com consequente exposição de colágeno e redução da microdureza (SLUTZKY-GOLDBERG et al., 2004). Assim, interpretou-se que a solução com maior concentração de íons cálcio apresentava, consequentemente, maior capacidade desmineralizante e possibilidade de limpeza aumentada.

No presente estudo, a análise da espectrometria apontou que as soluções de quitosana $0,2 \%$ e EDTA $15 \%$ apresentaram as maiores concentrações de íons cálcio, sem diferença estatisticamente significante entre elas. As menores concentrações foram observadas no grupo do ácido acético $1 \%$, enquanto o ácido cítrico $10 \%$ ocupou uma posição intermediária. Resultado similar foi observado no trabalho de Spanó et al. (2009), no qual os pesquisadores adotaram a espectrometria de absorção atômica em chama para avaliar o efeito desmineralizante de diferentes soluções irrigantes. Os autores observaram que o EDTA $15 \%$ apresentou as maiores concentrações de cálcio, seguido do ácido cítrico 10\%. O ácido acético apresentou concentrações do íon bastante baixas, semelhantes às encontradas no presente estudo. Analisando os resultados de ambos os trabalhos, parece existir uma relação direta entre a capacidade de remoção da smear layer e a quantidade de íons cálcio removidos do canal radicular. Esta relação foi observada, também, no experimento de Marques et al. (2006), que utilizando metodologia semelhante ao do presente estudo, verificaram que as soluções de EDTAC $17 \%$ e CDTA $17 \%$, além de promoverem a limpeza mais eficiente diante da solução de EGTA 17\%, apresentaram as maiores concentrações de íons cálcio após análise espectrométrica.

Pérez-Heredia et al. (2008) avaliaram o efeito desmineralizante EDTA 15\%, ácido cítrico $15 \%$, ácido fosfórico $5 \%$ e hipoclorito de sódio $2,5 \%$ sobre a dentina radicular. As amostras de cada grupo permaneceram nas soluções por diferentes períodos de tempo. Os resultados revelaram que maiores concentrações de cálcio foram extraídas das amostras de EDTA 15\% e ácido cítrico 15\%, sem diferença estatisticamente significante entre esses grupos. Tais resultados divergiram aos achados do presente estudo. A explicação deve-se aos fatores que interferem na eficiência dos agentes desmineralizantes, como o tempo de aplicação, o pH, a concentração da solução e a quantidade de solução disponível (ÇALT; SERPER, 2002; HÜLSMANN, HECKENDORFF, LENNON, 2003; MARQUES et al., 2006). A 
concentração do ácido cítrico utilizado por Pérez-Heredia et al. (2008) foi maior que a utilizada no presente estudo, o que provavelmente, atribuiu ao ácido efeito desmineralizante estatisticamente semelhante ao EDTA. A ação quelante do ácido cítrico torna-se maior à medida que se aumenta a sua concentração (REIS et al., 2008).

A análise espectrométrica para a quitosana a $0,2 \%$ revelou uma concentração média de $104,13 \mathrm{mg} \mathrm{L}^{-1}$, sem resultados estatisticamente significantes na comparação com o EDTA 15\% (121,80 $\left.\mathrm{mg} \mathrm{L}^{-1}\right)$. Se ambas as soluções apresentam efeito quelante semelhante, por uma questão econômica, a solução menos concentrada deve ser preferida. A fibra natural quitina, precursora da quitosana é a mais abundante na natureza depois da celulose. Em associação, as preocupações com o meio ambiente têm pressionado os pesquisadores para a substituição do EDTA, uma vez que a concentração desse produto está aumentando muito nos rios e lagos do hemisfério norte (SPANÓ, et al., 2009).

Os resultados satisfatórios apresentados pela quitosana a $0,2 \%$ nesse experimento, e diante das características diferenciais apresentadas por esse biopolímero (atoxidade, efeito antibacteriano, biodegradável, biocompatível) (SENEL; KAS; SQUIER, 2000; AKNCBAY; SENEL; AY., 2007), possibilita novas pesquisas no sentido de investigar o uso dessa substância como irrigante do canal radicular.

Estudos futuros são necessários para avaliar a ação da quitosana sobre a microdureza dentinária; uma possível interferência na adesão dos cimentos endodônticos e dos materiais restauradores; grau de erosão frente à estrutura dentinária, além da avaliação do comportamento dessa biomolécula nos tecidos periapicais. 



\section{CONCLUSÕES}

Com base na metodologia empregada e na análise dos resultados obtidos é lícito concluir que:

1- As soluções de EDTA $15 \%$, quitosana $0,2 \%$ e ácido cítrico $10 \%$ apresentaram capacidade, semelhante, de remover a smear layer do canal radicular.

2- Não houve diferença na capacidade de limpeza das soluções supracitadas quando comparados os terços médio e apical.

3- O ácido acético $1 \%$ não foi eficiente na limpeza das paredes do canal radicular.

4- As soluções de EDTA $15 \%$ e quitosana $0,2 \%$ removeram em maior quantidade íons cálcio do canal radicular, seguidos pelo ácido cítrico $10 \%$ e acido acético $1 \%$. 



\section{REFERÊNCIAS}

ABBOTT, P. V. Recognition and prevention of failures in clinical dentistry. Endodontics. Ann R Australas Coll Dent Surg., v. 11, p. 150 - 66, 1991.

AKNCBAY, H.; SENEL, S.; AY, Z. Y. Application of chitosan gel in the treatment of chronic periodontitis. J Biomed Mater Res B Appl Biomater., v. 80, n. 2, p. 290 296, 2007.

BALLAL, N. V.; SHAVI, G. V.; KUMAR ,R.; KUNDABALA, M.; SEETHARAMA, K. In Vitro Sustained Release of Calcium lons and $\mathrm{pH}$ Maintenance from Different Vehicles Containing Calcium Hydroxide. J Endod., v. 36, n. 5, p. 862 -866, 2010.

BLAIR, H. S.; HO, T-C. Studies in the adsorption and diffusion of ions in chitosan. Journal of Chemical Technology and Biotechnology, v. 31, p. 6-10, 1981.

BOYNUEĞRI, D; ÖZCAN, G.; ŞENEL, S.; UÇ, D.; URAZ, A.; ÖĞÜŞ, E.; ÇAKILCI, B.; KARADUMAN, B. Clinical and radiographic evaluations of chitosan gel in periodontal intraosseous defects: a pilot study. J Biomed Mater Res B Appl Biomater., v. 90, n. 1, p.461- 466, 2009.

ÇALT, S.; SERPER, A. Time dependent effects of EDTA on dentin structures. J. Endod., v. 28, n. 1, p. 17-19, 2002. 
CARVALHO, A. S; CAMARGO, C. H; VALERA, M. C.; CAMARGO, S. E.; MANCINI, M. N. Smear layer removal by auxiliary chemical substances in biomechanical preparation: a scanning electron microscope study. J Endod. v. 34, n. 11, p. 1396 400, 2008.

DOMARD, A. $\mathrm{pH}$ and c.d. measurements on a fully deacetylated chitosan: application to Cull-polymer interactions. International Journal of Biological Macromolecules, v. 9, p. 98 - 104, 1987.

ECONOMIDES, N.; LIOLIOS, E.; KOLOKURIS, I.; BELTES, P. Long-term evaluation of the influence of smear layer removal on the sealing ability of different sealers. $\mathbf{J}$ Endod., v. 25, n.2, p. 123-5, 1999.

ESTRELA, C.; LOPES, H. P.; ELIAS, C. N.; LELES, C. R.; PÉCORA, J. D. Limpeza da superfície do canal radicular pelo vinagre de maçã, hipoclorito de sódio, clorexidina e EDTA. Revista da Associação Paulista de Cirurgiões-Dentistas, v. 61, n. 2, p. $117-122,2007$.

FOCHER, B.; MASSOLI, A.; TORRI, G.; GERVASINI, A.; MORAZZONI, F. High molecular weight chitosan 6-O-sulphate, synthesis, ESR and NMR characterization. Makromolekulare Chemie., v. 187, p. 2609 - 2620, 1986.

GUIBAL, E.; MILOT, C.; ROUSSY, J. Influence of hydrolysis mechanisms on molybdate sorption isotherms using chitosan. Separation Science and Technology, v. 35, p.1020 - 1038, 2000.

HAZNEDAROĞLU, F. Efficacy of various concentrations of citric acid at different $\mathrm{pH}$ values for smear layer removal. Oral Surg Oral Med Oral Pathol Oral Radiol Endod., v. 96, n.3, p. 340 - 4, 2003.

HÜLSMANN, M.; HECKENDORFF, M.; LENNON, A. Chelating agents in root canal treatment: mode of action and indications for their use. Int. Endod. J., v. 36, n. 12, p. $810-830,2003$.

JAWORSKA, J. S.; SCHOWANEK, D.; FEIJTEL, T. C. Environmental risk assessment for trisodium [S,S] - ethylene diamine disuccinate, a biodegradable chelator used in detergent applications. Chemosphere. v. 38, n.15, p. 3597-625, 1999.

JEON, Y. J.; SHAHID, F.; KIN, S. K. Preparation of chitin and chitosan logomers and their applications in physiological functional foods. Food Reviews International, v. 16, n. 2, p.159 - 176, 2000.

KHEDMAT, S.; SHOKOUHINEJAD, N. Comparison of the efficacy of three chelating agents in smear layer removal. J Endod. v. 34, n. 5, p. 599 - 602, 2008. 
KLOKKEVOLD, P. R.; LEW, D. S.; ELLIS, D. G.; BERTOLAMI, C. N. Effect of chitosan on lingual hemostasis in rabbits. J Oral Maxillofac Surg, v. 49, n.8, p. 858 863, 1991.

KOKKAS, A. B.; BOUTSIOUKIS, A. C.; VASSILIADIS, L. P.; STAVRIANOS, C. K. The influence of the smear layer on dentinal tubule penetration depth by three different root canal sealers: an in vitro study. J Endod . v. 30, n. 2, p. 100 - 102, 2004.

KURITA, K. Chemistry and application of chitin and chitosan. Polymer Degradation and Stability, v. 59, n.1 - 3, p. $117-120,1998$.

MAHRAN, A. H.; ABOEL-FOTOUH, M. M. Comparison of Effects of ProTaper, HeroShaper, and Gates Glidden Burs on Cervical Dentin Thickness and Root Canal Volume by Using Multislice Computed Tomography. J Endod., v. 34, n. 10, p.1219 1222, 2008.

MAI, S.; KIM, Y. K.; AROLA, D. D.; GU, L. S.; KIM, J. R.; PASHLEY, D. H.; TAY, F. R. Differential aggressiveness of ethylenediamine tetraacetic acid in causing canal wall erosion in the presence of sodium hypochlorite. J Dent., v. 38, n. 3, p. $201-6,2010$.

MANCINI, M.; ARMELLIN, E.; CASAGLIA, A.; CERRONI, L.; CIANCONI, L. A comparative study of smear layer removal and erosion in apical intraradicular dentine with three irrigating solutions: a scanning electron microscopy evaluation. J Endod., v. 35, n. 6, p. $900-903,2009$.

MARQUES, A. A. F.; MARCHESAN, M. A.; SOUSA-FILHO, C. B.; SILVA-SOUSA, Y. T. C.; SOUSA-NETO, M. D.; CRUZ-FILHO, A. M. Smear Layer Removal and Chelated Calcium Ion Quantification of Three Irrigating Solutions. Braz Dent J, v. 17, n.4, p. 306 - 309, 2006.

MELLO, I.; KAMMERER, B. A.; YOSHIMOTO, D.; MACEDO, M. C. S.; ANTONIAZZI, $\mathrm{J}$. H. Influence of final rinse technique on ability of Ethylenediaminetetraacetic Acid of removing smear layer. J Endod., v. 36, n. 3, p. 512 - 514, 2010.

MUZZARELLI, R. A.; MATTIOLI-BELMONTE, M.; TIETZ, C.; BIAGINI, R.; FERIOLI, G.; BRUNELLI, M. A.; FINI, M.; GIARDINO, R.; ILARI, P.; BIAGINI, G. Stimulatory effect on bone formation exerted by a modified chitosan. Biomaterials, v. 15, n.13, p. $1075-1081,1994$. 
ONSØYEN, E; SKAUGRUD, O. Metal recovery using chitosan. J Chem Technol Biotechnol., v. 49, n. 4, p. 395 - 404, 1990.

ORSTAVIK, D; HAAPASALO, M. Disinfection by endodontic irrigants and dressings of experimentally infected dentinal tubules. Endod Dent Traumatol., v. 6, n. 4, p. $142-9,1990$.

PAPAGIANNI, M. Advances in citric acid fermentation by Aspergillus niger: Biochemical aspects, membrane transport and modeling. Biotechology Advances, v. 25 , n. 3, p. $244-63,2007$.

PARK, J. S.; CHOI, S. H.; MOON, I. S.; CHO, K. S.; CHAI, J. K.; KIM, C. K. Eight week histological analysis on the effect of chitosan on surgically created one-wall intrabony defects in beagle dogs. J Clin Periodontol., v. 30, n. 5, p. 443 - 53, 2003.

PARK, S. S.; KIM, S. G.; LIM, S. C.; ONG, J. L. Osteogenic activity of the mixture of chitosan and particulate dentin. J Biomed Mater Res A. v. 87, n. 3, p. 618 - 23, 2008.

PÉCORA, J. D.; CAPELLI, A.; SEIXAS, F. H.; MARCHESAN, M. A.; GUERISOLI, D. M. Z. Biomecânica Rotatória: Realidade ou Futuro? Revista da Associação Paulista de Cirurgiões Dentistas, São Paulo, v.56, p. 4 - 6, 2002.

PÉREZ-HEREDIA, M.; FERRER-LUQUE, C. M.; GONZÁLEZ-RODRÍGUEZ, M. P.; MARTÍN-PEINADO, F. J.; GONZÁLEZ-LÓPEZ, S. Decalcifying effect of 15\% EDTA, $15 \%$ citric acid, $5 \%$ phosphoric acid and $2.5 \%$ sodium hypochlorite on root canal dentine. Int. Endod. J., v. 41, n. 15, p. 418 - 423, 2008.

PETER, M. G. Applications and environmental aspects of chitin and chitosan. J. Macromol. Sci., v. A32, p. 629 - 640, 1995.

PIRON, E.; DOMARD, A. Interaction between chitosan and uranyl ions. Part 2. Mechanism of interaction. International Journal of Biological Macromolecules, v. 22, n. 1, p. $33-40,1998$.

PRADO, M.; GUSMAN, H.; GOMES, B. P. F. A.; SIMÃO, R. A. Scanning Electron Microscopic Investigation of the Effectiveness of Phosphoric Acid in Smear Layer Removal When Compared with EDTA and Citric Acid. J Endod., v. 37, n. 2, p. 255 258, 2011.

RHAZI, M; DESBRIÈRES, J.; TOLAIMATE, A.; RINAUDO, M.; VOTTERO P.; ALAGUI, A.; MERAY M. EL. Influence of the nature of the metal ions on the 
complexation with chitosan. Application to the treatment of liquid wast. European Polymer Journal. v. 38 , p. 1523 - 1530, 2002.

REIS, C.; DE-DEUS, G.; LEAL, F.; AZEVEDO, E.; COUTINHO-FILHO, T.; PACIORNIK, S. Strong effect on dentin after the use of high concentrations of citric acid: na assessment with co-site optical microscopy and ESEM. Dent. Mater., v. 24, n. 12, p. 1608 - 1615, 2008.

SCELZA, M. F.; PIERRO, V.; SCELZA, P.; PEREIRA, M. Effect of three different time periods of irrigation with EDTA-T, EDTA, and citric acid on smear layer removal. Oral. Surg. Oral Med. Oral Pathol. Oral Radiol. Endod., v. 98, n. 4, p. 499 - 503, 2004.

ŞEN, B. H.; ERTÜRK, Ö.; PIŞKIN, B. The effect of different concentrations of EDTA on instrumented root canal walls. Oral Surg. Oral Med. Oral Pathol. Oral Radiol. Endod., v. 108, n. 4, p. 622 - 627, 2009.

SEN, B. H.; WESSELINK, P. R.; TÜRKÜN, M. The smear layer: a phenomenon in root canal therapy. Int Endod J., v. 28, n.3, p. 141- 8, 1995.

SENEL, S.; KAS, H. S.; SQUIER, C. A. Application of chitosan in dental drug delivery and therapy. In: Muzzarelli RAA, editor. Chitosan Per os: From Dietary Supplement to Drug Carrier. Italy: Atec, Grottammare; p. 241 - 256, 2000.

SENEL, S.; IKINCI, G.; KAS, S.; YOUSEFI-RAD, A.; SARGON, M. F.; HINCAL, A. A. Chitosan films and hydrogels of chlorhexidine gluconate for oral mucosal delivery. Int J Pharm., v. 193, n.2, p. 197 - 203, 2000.

SHAHRAVAN, A.; HAGHDOOST, A. A.; ADL, A.; RAHIMI, H.; SHADIFAR, F. Effect of smear layer on sealing ability of canal obturation: a systematic review and meta-analysis. J Endod. v. 33, n. 2, p. 96 - 105, 2007.

SILVA, L. A.; SANGUINO, A. C.; ROCHA, C. T.; LEONARDO, M. R.; SILVA R. A. Scanning electron microscopic preliminary study of the efficacy of SmearClear and EDTA for smear layer removal after root canal instrumentation in permanent teeth. $\mathbf{J}$ Endod. v. 34, n. 12, p. 1541- 4, 2008.

SLUTZKY- GOLDBERG, I.; MAREE, M.; LIBERMAN, R.; HELING, I. Effect of sodium hypochlorite on dentin microhardness. J. Endod., v. 30, n. 12, p. $880-882,2004$. 
SPANÓ, J. C. E.; SILVA, R. G.; GUEDES, D. F. C.; SOUSA-NETO, M. D.; ESTRELA, C.; PÉCORA, J. D. Atomic absorption spectrometry and scanning electron microscopy evaluation of concentration of calcium ions and smear layer removal with root canal chelators. J Endod., v. 35, n. 5, p. 727- 730, 2009.

TORABINEJAD, M.; HANDYSIDES, R.; KHADEMI, A. A.; BAKLAND, L. K. Clinical implications of the smear layer in endodontics: a review. Oral Surg Oral Med Oral Pathol Oral Radiol Endod., v. 94, n. 6, p. 658 - 66, 2002.

TORABINEJAD, M; KHADEMI, A. A.; BABAGOLI, J.; CHO, Y.; JOHNSON, W. B; BOZHILOV, K.; KIM, J.; SHABAHANG, S. A new solution for the removal of the smear layer. J Endod. v. 29, n. 3, p. 170 - 5, 2003.

VIOLICH, D. R.; CHANDLER, N. P. The smear layer in endodontics - a review. Int Endod J., v. 43, n.1, p. 2 - 15, 2010.

WU, Y.; HU, Y.; CAI, J.; MA, S.; WANG, X. Coagulation property of hyaluronic acidcollagen/chitosan complex film. J. Mater. Sci. Mater. Med., v. 19, n. 12, p. 3621 3629, 2008.

ZHANG, K.; TAY, F. R.; KIM, Y. K.; MITCHELL, J. K.; KIM, J. R.; CARRILHO, M.; PASHLEY, D. H.; LING, J. Q. The effect of initial irrigation with two different sodium hypochlorite concentrations on the erosion of instrumented radicular dentin. Dent Mater. v. 26, n. 6, p. $514-23,2010$. 


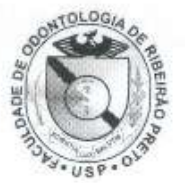

\section{UNIVERSIDADE DE SÃO PAULO}

Faculdade de Odontologia de Ribeirão Preto Comitê de Êtica em Pesquisa

Of.ATAC.CEP/10811/FORP-USP/18.03.2011

CHLS/fdc

Ref. processo $n .{ }^{\circ}$ 2011.1.205.58.6

Senhor(a) Pesquisador(a):

CAAE n. ${ }^{\circ} 0015.0 .138 .000-11$

Informamos que o Comitê de Ética em Pesquisa, em sua $118^{a}$ Sessão, realizada em 17 de março de 2011, aprovou o desenvolvimento do projeto de pesquisa envolvendo seres humanos, intitulado "Avaliaçâa da capacidade de limpeza do canal radicular por meio de agentes quelantes e desmineralizantes: estudo ex vivo por MEV e espectrofotometria dos compostos".

$\mathrm{Na}$ oportunidade, lembramos da necessidade de ser entregue, na secretaria do CEP. - Relatório Final em 17/03/2012, com o respectivo formulário preenchido pelo pesquisador responsàvel.

Lembramos ainda que, quando da submissăo do relatório a este Comitê, quaisquer inclusōes ou modificaçóes no projeto original deverăo ser comunicadas e justificadas ao CEP, através do formulário supracitado.

Fabricio Dias de Carvalho

Secretário "ad doc" do Comitê de Ética em Pesquisa

IImo(a). Sr(a).

PG. POLLIANA VILAÇA SILVA (Prof. Dr. Antonio Miranda da Cruz Filho)

Departamento de Odontologia Restauradora

desta Faculdade

AVENIDA DO CAFÉ, S/N," - TEL. (16) $3602-4123 / 3963$ - FAX (16) 3602.4102
14040-904-RIBEIRÃOPRETO - SP-BRASIL. 